\title{
KAT3B-p300 and H3AcK18/H3AcK14 levels are prognostic markers for kidney ccRCC tumor aggressiveness and target of KAT inhibitor CPTH2
}

Elisa Cocco ${ }^{1}$, Manuela Leo ${ }^{2}$, Claudia Canzonetta ${ }^{3}$, Serena Di Vito ${ }^{4}$, Antonello Mai ${ }^{5}$, Dante Rotili ${ }^{5}$, Arianna Di Napoli ${ }^{1}$, Andrea Vecchione ${ }^{1}$, Cosimo De Nunzio ${ }^{6}$, Patrizia Filetici ${ }^{4^{*}}$ (D) and Antonella Stoppacciaro ${ }^{1 *}$

\begin{abstract}
Background: Kidney cancer and clear cell renal carcinoma (ccRCC) are the 16th most common cause of death worldwide. ccRCC is often metastasized at diagnosis, and surgery remains the main treatment; therefore, early diagnosis and new therapeutic strategies are highly desirable. KAT inhibitor CPTH2 lowers histone H3 acetylation and induces apoptosis in colon cancer and cultured cerebellar granule neurons. In this study, we have evaluated the effects of CPTH2 on cCRCC 786-O cell line and analyzed drug targets expressed in ccRCC tumor tissues at different grade.

Results: CPTH2 decreases cell viability, adhesion, and invasiveness in cCRCC cell line 786-O. It shows preferential inhibition for KAT3B-p300 with hypoacetilating effects on histone H3 at specific H3-K18. Immunohistochemical analysis of 70 cCRCC tumor tissues compared with peritumoral normal epithelium showed a statistical significant reduction of p300/H3AcK18 paralleled by an increase of H3AcK14 in G1 grade and an opposed trend during tumor progression to worst grades. In this study, we demonstrate that these marks are CPTH2 targets and significative prognosticators of low-grade ccRCC tumor.

Conclusions: $c$ RCC is substantially insensitive to current therapies, and the efficacy of clinical treatment is dependent on the dissemination stage of the tumor. The present study shows that CPTH2 is able to induce apoptosis and decrease the invasiveness of a cCRCC cell line through the inhibition of KAT3B. In a tumor tissue analysis, we identified new prognosticator marks in grade G1 ccRCC tumors. Low KAT3B/H3AcK18 vs. high H3AcK14 were found in G1 while an opposed trend characterized tumor progression to worst grades. Our collected results suggest that CPTH2 reducing KAT3B and H3AcK18 can be considered a promising candidate for counteracting the progression of ccRCC tumors.
\end{abstract}

Keywords: CPTH2, KAT3B-p300, ccRCC, Tumor tissues, H3-AcK18

\footnotetext{
* Correspondence: patrizia.filetici@uniroma1.it; antonellastoppacciaro@uniroma1.it

${ }^{4}$ Institute of Molecular Biology and Pathology-CNR, La Sapienza University of

Rome, P.le, A. Moro 5, Rome, Italy

'Surgical Pathology Units, Department of Clinical and Molecular Medicine,

Ospedale Sant'Andrea, La Sapienza University, Rome, Italy

Full list of author information is available at the end of the article
} 


\section{Background}

Kidney cancer is classified as the 16th most common cause of death from cancer worldwide [1]. The majority of kidney cancers $(70 \%)$ are classified as clear cell renal carcinoma (ccRCC), at average age of diagnosis (60-64 years) [2]. It is often metastasized [3]; therefore, identification of new therapeutic strategies is highly desirable. ccRCC is associated with VHL loss of function with stabilization of hypoxia inducible factors (HIF- $1 \alpha$ and HIF- $2 \alpha$ ) in both sporadic and familial forms [4]. Recent studies highlighted major roles for epigenetic regulation in the development and progression of the disease. Several epigenetic regulators such as SWI/SNF polybromo PBRM1, histone deubiquitinase BAP1, methyltransferase SETD2, and acetyltransferase MYST1 (KAT8) are significantly altered in ccRCC [5-8]. Noteworthy, global levels of histone $\mathrm{H} 3$ acetylation has been correlated with disease progression $[9,10]$ suggesting that histone modifications are tightly linked to ccRCC. The K-histone acetyl transferase KAT3B (p300) could play a role [11], and its overexpression is detected in the most aggressive cases of hepatocellular carcinoma [12]. In prostate cancer, KAT3B promotes tumor growth and activation of androgen receptor [13] weakens invasiveness in melanoma, breast, and prostate cancer cell lines [14-16]. Its nuclear localization is linked to pro-tumoral effects while cytoplasmic to a less severe outcome [17]. Epigenetic drugs are potential tools for pharmacological research and therapeutic applications. HDAC inhibitors have been extensively studied as potential anticancer treatment; however, they exhibit different effects across various renal cell lines [18]. On the other hand, there is little information on the use of K-acetyltransferase inhibitors (KATi). Nonetheless, some of them were shown to prevent growth in a broad panel of cancer cells lines $[19,20]$ such as neuroblastoma and glioma [21, 22]. In the past, we identified a novel KAT inhibitor, cyclopentylidene-[4-(4chlorophenyl)thiazol-2-yl)hydrazone (CPTH2), in yeast [23]. CPTH2 was tested in different experimental models with effects on axon outgrowth [24], adenovirus infection [25], expression of superoxide dismutase in human monocytes [26], and impaired antibody response in B lymphocytes [27]. In colon adenocarcinoma, CPTH2 lowers cancer growth, decreasing GCN5 activity regulated by cMyc/E2F1 [28]. In the presented study, we assessed the effects of CPTH2 on K1 papillary thyroid and ccRCC 786-O cell lines. CPTH2 lowered KAT activity of nuclear cell extracts showing specificity for KAT3B. Importantly, it lowered cell viability, impaired invasiveness and migration, and modified cell adhesion with a global effect on cytoskeleton organization. We also analyzed the effects of the drug on the acetylation of histone $\mathrm{H} 3$ globally and at selected residues, and we found a hypoacetilating effects at specific H3AcK18. The results obtained by treating the cells with CPTH2 were comparable with the effects induced by silencing KAT3B, thus confirming the inhibitory selectivity of
CPTH2 for KAT3B in 786-O cell line. The collected experimental results on cell lines were paralleled by a detailed analysis of KAT3B broad distribution and global levels of histone H3AcK14 and H3AcK18 in 70 ccRCC patients. Tumor and normal tissues from kidney specimens at different grades and stages were compared. Notably, we found a sudden increase of H3AcK18 and KAT3B in the switch from G1 to G2 tumor grade. Surprisingly, this effect was paired by a progressive decrease of H3AcK14 levels. This analysis suggests a novel approach and identifies promising prognosticators in clear cell carcinoma.

\section{Methods}

\section{Cell cultures and treatment with CPTH2}

786-O human ccRCC cell line (ATCC, Manassas, VA) was grown in RPMI 1640 plus 10\% FBS, $2 \mathrm{mM}$ L-glutamine, $25 \mathrm{U} / \mathrm{ml}$ penicillin, and $25 \mathrm{U} / \mathrm{ml}$ streptomycin (Gibco, Thermo Fisher Scientific, Waltham, MA). K1 human thyroid carcinoma cell line (ECACC, Sigma-Aldrich, St. Louis, MO) was cultured in DMEM:Hamm's F12:MCDB 105 medium (2:1:1) plus 10\% FBS, 2 mM L-glutamine, $25 \mathrm{U} / \mathrm{ml}$ penicillin, and $25 \mathrm{U} / \mathrm{ml}$ streptomycin (Gibco, Thermo Fisher Scientific). Cells were maintained in a humidified atmosphere of $5 \% \mathrm{CO}_{2}$ at $37{ }^{\circ} \mathrm{C}$. Cyclopentylidene-[4-(4chlorophenyl) thiazol-2-yl)hydrazone (CPTH2) was dissolved in $100 \mathrm{mM} / \mathrm{L}$ dimethyl sulfoxide (DMSO; Sigma-Aldrich) and diluted to the final concentrations in complete medium. For all the experiments, cells were treated with 1\% DMSO as control. After $24 \mathrm{~h}$ from seeding, exponentially growing 786-O and $\mathrm{K} 1$ tumor cells were treated with $\mathrm{CPTH} 2$ at concentrations ranging from 1 to $200 \mu \mathrm{mol} / \mathrm{L}$ for 24 to $120 \mathrm{~h}$; 24-48 h culture and $100 \mathrm{mM} / \mathrm{L}$ were then chosen as $\mathrm{CPTH} 2$ concentration giving the strongest growing inhibitory effects without signs of cell damage or exhaustion of the drug function [29].

\section{CPTH2 stability}

$2.9 \mathrm{mg}$ of CPTH2 (MW 291.80) have been dissolved in 0. $3 \mathrm{ml}$ of DMSO and then diluted with PBS buffer $(\mathrm{pH}=7$. 4) to $2 \mathrm{ml}(5 \mathrm{mM})$. Then, the resulting solution was incubated at $37{ }^{\circ} \mathrm{C}$ on a heating block and checked for purity after different times (30 $\mathrm{min}, 1,2,12,24,36,48,72$, and $132 \mathrm{~h}$ ) by Thin Layer Chromatography (TLC) on silica gel plates eluting with the mixture Ethyl Acetate:Petroleum Ether (1:2). Over time, no traces of degradation products were detected by TLC. CPTH2 is stable in PBS buffer at $37{ }^{\circ} \mathrm{C}$ since no traces of degradation products can be detected by TLC up to $132 \mathrm{~h}$ of incubation.

\section{In vitro HAT assay}

Histone acetyltransferase activity was measured with fluorescent in vitro HAT Assay Kit (Active Motif, CA) in nuclear extracts $(7 \mu \mathrm{g})$ prepared with EpiQuik ${ }^{\mathrm{TM}}$ Nuclear Extraction Kit I (Epigentek, NY) treated 24 or 48 h with 
CPTH2 $100 \mu \mathrm{M}$ or solvent DMSO. Twenty-five micrograms of recombinant proteins p300 (Active Motif), GCN5 (Active Motif), and PCAF (Biomol, DE) were incubated with Anacardic Acid $15 \mu \mathrm{M}, \mathrm{CPTH} 2400 \mu \mathrm{M}$, and $600 \mu \mathrm{M}$ or in DMSO. HAT activity was measured in tubes in presence of Ac-CoA $(0.5 \mathrm{mM})$ and histone $\mathrm{H} 3$ $(50 \mu \mathrm{M})$. Resulting fluorescence was measured with Glo$\mathrm{Max}^{\circ}$ (Promega, WI) after conjugation between developer and free sulfhydryl groups on CoA-SH.

\section{Cell viability and apoptosis assay}

Percentage of viable cells was evaluated by trypan blue dye exclusion method. After monolayer cell trypsinization (0. $25 \mathrm{mg} / \mathrm{ml}$ trypsin, Gibco, Thermo Fisher Scientific), cells were stained with trypan blue (0.04\%, Gibco) for $2 \mathrm{~min}$, and vital, unstained cells were counted with emacytometer. The percentage of unstained cells was obtained as mean \pm SD of four independent experiments. 786-O cell apoptosis was assayed with MuseAnnexinV and Dead Cell kit (Millipore, Darmstadt, DE); $1 \times 10^{5}$ cells from untreated, DMSO and CPTH2 samples were centrifuged (2000 rpm, $5 \mathrm{~min}$ ), washed in PBS, and resuspended in PBS plus 1\% BSA (Sigma-Aldrich) 1\% FBS, with $100 \mu \mathrm{L}$ of Dead Cell reagent containing AnnexinV and 7-aminoactinomycin D (7-AAD). After $20 \mathrm{~min}$ RT incubation at room temperature in the dark, cells were applied to a Muse Cell Analyzer (Millipore) , and the results are expressed as percentage of apoptotic cells \pm SD.

\section{In vitro migration, invasiveness, and adhesion}

Migratory and invasive capacities of $786-\mathrm{O}$ cells were evaluated using the BioCoat Invasion Chamber system (BD Biosciences, San Jose, CA). Matrigel invasion chambers, containing an 8- $\mu \mathrm{m}$-pore-size PET membrane, were treated with Matrigel Basement Membrane Matrix (invasion test; BD Bioscience) or with BSA (migration test; Sigma); $\sim 1.5 \times 10^{5}$ cells diluted in $0.2 \%$ FBSDMEM were added to upper compartment and $2.5 \mathrm{ml}$ $10 \%$ FBS-DMEM to the lower compartment. Migration assay was performed for 24 and $48 \mathrm{~h}$ in a humidified tissue culture incubator at $37{ }^{\circ} \mathrm{C}$ in a $5 \% \mathrm{CO}_{2}$ atmosphere. After incubation, no migrating cells were removed by scrubbing the upper face of the membrane, and migrated cells present on the lower surface of the membrane were stained with Diff-Quick; cells present in 10,400x enlargement field were counted in each filter. The data are given as mean $\pm \mathrm{SD}$ of triplicate filters. For adhesion test, a 96-well plate was coated with BSA $(5 \mathrm{mg} / \mathrm{ml}$, SigmaAldrich), fibronectin (5 $\mu \mathrm{g} / \mathrm{ml}$, bovine, Calbiochem), matrigel ( $3 \mathrm{mg} / \mathrm{ml}$, standard matrigel matrix, BD Biosciences), and collagen type IV $(5 \mu \mathrm{mg} / \mathrm{ml}$, bovine, SigmaAldrich). Cells treated for 24 and $48 \mathrm{~h}$ with CPTH2 or DMSO were plated $5 \times 10^{4}$ on each coated well in triplicate and incubated to allow adhesion at $37{ }^{\circ} \mathrm{C}$ for
$1 \mathrm{~h}$. After PBS washing, cells were fixed in ice-cold acetone/ethanol (1:1, Sigma-Aldrich) for $10 \mathrm{~min}$ and washed with $20 \%$ methanol. Cells stained with crystal violet solution $(0.5 \% w / v$ in $20 \%$ methanol, Sigma-Aldrich) were measured in a spectrophotometer at $540 \mathrm{~nm}$ (Multiskan spectrum, Thermo) after color solubilization with $0.1 \mathrm{M}$ sodium citrate $\mathrm{pH} 4.2$ (50\% EtOH, Sigma-Aldrich).

\section{Scratch assay}

Cell migration was tested with "wound healing" assay [30]. Briefly, 786-O cells were seeded in a 6-well plate and cultured until confluence, scraped with a 200- $\mu \mathrm{l}$ micropipette tip, then incubated with CPTH2 $(100 \mu \mathrm{M})$, DMSO, or RPMI; the growth was photographed at 0 and $48 \mathrm{~h}$ with an inverted microscope (Nikon Eclipse TE2000-S) and digital camera (Nikon Coolpix S4, 6.0 Mpix, 10× zoom). Wound area was measured and quantified with TScratch Software [31].

\section{RNA interference}

18-20 h before transfection, 786-O were plated in 6-well plates in complete growth medium; at $60 \%$ of confluency, cells were placed in OptiMEM (serum-and antibiotics-free medium; Thermo Fisher Scientific) and transfected with $30 \mathrm{nM}$ of p300 small interfering RNA (HSC.RNAII.N001429.12.1, IDT, San Jose, CA) or Negative Control 1 (IDT) using Lipofectamine 2000 according to the manufacturer (Invitrogen, Thermo Fisher). Six hours after transfection, the medium was changed to full growth conditions, and cells were harvested at 6, 12, 24, and $48 \mathrm{~h}$ post-transfection. p300si efficiency was assessed by real-time PCR transcript analysis of p300 mRNA.

\section{Immunofluorescence}

786-O cells were seeded on glass coverslips in $35 \mathrm{~mm}$ Petri dishes and cultured until 50\% confluence. They were treated with CPTH2 $(100 \mu \mathrm{M})$ for $18 \mathrm{~h}$ or transfected with $30 \mathrm{nM}$ si-p300 for $24 \mathrm{~h}$, washed three times with PBS and fixed with $4 \%$ paraformaldehyde (PFA; Sigma-Aldrich) in PBS, permeabilized with $0.2 \%$ Triton X-100 (Sigma-Aldrich), and blocked with 1\% BSA. Then, they were incubated with rhodamine-phalloidin (1:1000, Thermo Fisher Scientific) in 2\% BSA in PBS for $1 \mathrm{~h}$, washed with PBS, and stained with DAPI (1:10000, $1 \mathrm{mg} / \mathrm{mL}$ stock solution, Roche, Basel, $\mathrm{CH})$. Images were acquired with the Nikon fluorescent microscopy, and stress fibers were counted by analyzing 100 cells in different fields for each experimental point. The data are given as mean \pm SEM of stress fiber numbers per cell.

\section{RNA isolation and real-time PCR analysis}

Total RNA was isolated from 786-O cell line with TRIzol reagent (Ambion, Thermo Fisher), quantified with 
Nanodrop 2000 (Thermo Fisher). Two hundred fifty nanograms of total RNA were reverse transcribed with HighCapacity RNAtocDNA Reverse Trascription kit (Applied Biosystems, Thermo Fisher). Real-time PCR was performed in Stratagene Mx3005P (Agilent Technologies, Santa Clara, CA) with TaqMan2X Universal Master Mix (Applied Biosystems) in $20 \mu \mathrm{l}$ mixture. Each sample assayed in triplicate was performed with PCR cycles: $(10 \mathrm{~min})$ at $95{ }^{\circ} \mathrm{C}$ and 60 cycles of $(15 \mathrm{~s})$ at $95^{\circ} \mathrm{C}$ and a final $(1 \mathrm{~min})$ at $60{ }^{\circ} \mathrm{C}$. The primers and probes of the following transcripts were EP300 (Hs00914223_m1), AKT-1 (Hs00178289_m1), TGF-b2 (Hs00234244_m1), HIF-1a (Hs00153153_m1), CD44 (Hs01075864_m1), ITGb1 (Hs01127536_m1), ITGb3 (Hs01001469_m1), ITGa5 (Hs01547673_m1), and ITGa6 (Hs01041011_m1) (Applied Biosystems). The fold change of gene expression was calculated using the 2- $\Delta \Delta C T$ method, and all values were normalized to endogenous control ACTB (Hs 99999903_m1, Applied Biosystems) and expressed in arbitrary units.

\section{Bulk histone preparations and western blot analysis} Cells were seeded at 200,000 per well, after $24 \mathrm{~h}$ were treated with $\mathrm{CPTH} 2, \mathrm{DMSO}, \mathrm{p} 300 s i, \mathrm{NC} 1$ and incubated at $37^{\circ} \mathrm{C}$ for 12,24 , and $48 \mathrm{~h}$ in a humidified atmosphere of $5 \% \mathrm{CO}_{2}$. Total protein extracts were resuspended in Laemmli buffer (Bio-Rad, CA) and heated 5 min at $90^{\circ}$ C. Protein extracts were run on 15\% SDS-PAGE, blotted onto nitrocellulose (GE Healthcare Life Sciences, UK) and hybridized with anti-H3AcK18 (Abcam, UK), antiH3Ac (Merck, Germany), and anti-GAPDH (Santa-Cruz, TX) antibodies. Fluorescence detected by Long Lasting Chemilumiscent Substrate (EuroClone, Italy) was visualized by ChemiDoc ${ }^{\text {Tw }}$ MP Imaging System (Bio-Rad).

\section{Tissue samples and immunohistochemistry}

Clear cell RCC tissues and matched normal adjacent tissues were collected from 70 patients (listed in Table 1) with primary ccRCC between January 2008 and December 2014, who underwent kidney tumor radical surgery at the Sant'Andrea Hospital of Roma "La Sapienza" University. The use of the histological material was authorized by personal patient consensus according to S. Andrea Hospital policy form. Patient medical records including tumor staging, pathological diagnosis, and surgical data were reviewed and classified according to the American Joint Committee on Cancer [32]. Formalin-fixed and paraffinembedded ccRCC tissue blocks were sectioned, deparaffinized in xylene, and rehydrated through a graded ethanol series and then subjected to antigen retrieval by boiling in $0.01 \mathrm{M}$ sodium citrate buffer ( $\mathrm{pH}$ 6) $10 \mathrm{~min}$ in microwave. Endogenous peroxidase was blocked for $10 \mathrm{~min}$ in $3 \%$ hydrogen peroxide in methanol, incubated $1 \mathrm{~h}$ RT with primary antibody diluted to anti-p300 rabbit polyclonal antibody 1:1000 (Bethyl Laboratories), anti-H3AcK18 1: 2000 (Abcam), and anti-H3AcK14 1:2000 (Abcam). Reactions were followed with DAB detection kit (Dako). Immunostaining results were recorded as percentage of positive cells in increments of $10 \%$ regardless of the intensity of the staining. Cases were considered as negative if $<$ $5 \%$ of tumor cells were positive. Immunohistochemical and morphological analyses were evaluated by pathologists (AS and AV).

ICC

$10^{4}$ si-p300 cells untreated and treated in DMSO w/w $\mathrm{CPTH} 2$ were spotted on glass slide using cytocentrifuge (Cytospin3 Seongkohn traders, Korea) at $700 \mathrm{rpm}$ for $5 \mathrm{~min}$; slides were fixed with cold acetone for $15 \mathrm{~min}$, allowed to dry, and stored in PBS at $4{ }^{\circ} \mathrm{C}$. The cell spots were incubated with primary antibody as previously described.

\section{Statistical analysis}

Experiments were performed in triplicate and results recorded. Cell line data were presented as mean \pm standard deviation (SD). Statistical analysis was performed using the S-PSS 12.0 software. Evaluation of data distribution showed a non-normal distribution of the study data set. Differences between groups of patients in medians for quantitative variables and differences in distributions for categorical variables were tested with the Kruskal-Wallis one-way analysis of variance and chi-square test, respectively. Using multiple logistic regression with the enter method, variables as assessed in the univariate

Table 1 Patients characteristic

\begin{tabular}{|c|c|c|c|c|}
\hline & Number of cases & $\begin{array}{l}\text { Age } \pm \text { SD } \\
\text { (range) }\end{array}$ & $\begin{array}{l}\text { Tumor grade [41] } \\
\text { (WHO-UISP2011) }\end{array}$ & $\begin{array}{l}\text { Tumor stage [32] } \\
\text { pTNM }\end{array}$ \\
\hline Cases & 70 & $\begin{array}{l}64.21 \pm 11.24 \\
(29-91)\end{array}$ & $\begin{array}{l}\mathrm{G} 1=20 \\
\mathrm{G} 2=26 \\
\mathrm{G} 3=24\end{array}$ & Stage $1=35$ Stage $2=16$ Stage $3=16$ Stage $4=1$ \\
\hline Male & 46 & $\begin{array}{l}64.63 \pm 11,84 \\
(29-91)\end{array}$ & $\begin{array}{l}\mathrm{G} 1=15 \\
\mathrm{G} 2=16 \\
\mathrm{G} 3=15\end{array}$ & Stage I = 23Stage $\|=9$ Stage $I \|=12$ Stage $I V=1$ \\
\hline Female & 24 & $\begin{array}{l}63.42 \pm 10.18 \\
(45-79)\end{array}$ & $\begin{array}{l}\mathrm{G} 1=5 \\
\mathrm{G} 2=10 \\
\mathrm{G} 3=9\end{array}$ & Stage I $=12$ Stage $\|=7$ Stage $I I I=4$ Stage $I V=0$ \\
\hline
\end{tabular}


analysis were entered and investigated as predictors of ccRCC G2-G3 versus G1 and in a separate model predictors of high stage (stages II-III) versus low stage (stage I) were compared. The logistic regression analysis was carried out using the data from patients for whom complete data were available. The variables considered for entry into the model included age, p300, H3AcK14, and H3AcK18. An alpha value of $5 \%$ was considered as the threshold for significance. The data are presented as mean \pm standard deviation (SD); in vitro HAT assay, RTPCR, and western blot analysis were presented as mean \pm SEM. Student $t$ test was calculated, and $p$ value $\leq 0.05$ was considered significant. Odds ratios and 95\% CIs were calculated for the parameters in each group using ccRCC G1 and ccRCC stage I as a reference group.

\section{Results}

\section{CPTH2 inhibits HAT activity and decreases tumor cell} viability through apoptosis

Papillary thyroid (K1) and clear cell Renal Cell Carcinoma (ccRCC-786-O) cell lines were incubated with $\mathrm{CPTH} 2$ at the most effective concentration of $100 \mu \mathrm{M}$ in comparison with untreated and excipient (DMSO) controls (Fig. 1). In vitro HAT activity was measured in $24 \mathrm{~h} \mathrm{~K} 1$ and $48 \mathrm{~h} \mathrm{786-O}$ treated cells, respectively, depending on the responsiveness of individual cell lines. Despite intrinsic levels of HAT activity been higher in $\mathrm{K} 1$ than in 786-O, CPTH2 treatment caused a comparable drop of the activity in both lines (Fig. 1a), according to a direct enzyme's inhibition of the drug. To investigate the capacity of $\mathrm{CPTH} 2$ to affect cell proliferation, cells were treated in DMSO w/w CPTH2 for 12, 24, and $48 \mathrm{~h}$ and washed and the number of cells adjusted by day exclusion and cultured in medium. CPTH2 treatment caused a decrease in cell proliferation after as early as $12 \mathrm{~h}$ with a further significant reduction after $48 \mathrm{~h}$ stimulation. K1 cell line, which is derived from papillary thyroid carcinoma and is responsive to chemotherapy and apoptotic drugs, showed a reduction of $80 \%$ after $48 \mathrm{~h}$. ccRCC-786-O, which is from renal clear cell carcinoma and is much less sensitive to anti-proliferative drugs, presented a significant, but less pronounced, decrease, $40 \%$ (Fig. 1b). In order to demonstrate whether CPTH2 affected the cell cycle FACS analysis was performed confirming that no relevant defects in cell cycle progression were induced in ccRCC 786-O cells after $48 \mathrm{~h}$ treatment with $\mathrm{CPTH} 2$ (Fig. 1c). CPTH2 was also unable to change cell cycle progression in ccRCC 786-O and $\mathrm{K} 1$ papillary thyroid cells treated with prolonged treatment (Additional file 1). Accordingly, no substantial differences were obtained when 786-O cells were treated for 24 and $48 \mathrm{~h}$ in DMSO $w / w \mathrm{CPTH} 2$ as shown in the immunostaining with Ki67 and Cyclin D1 antibodies (Additional file 2). Annexin-V FACS analysis of K1 and
786-O cell lines showed in addition that $\mathrm{CPTH} 2$ treatment produced a drastic increase in apoptotic/dead cell population after $48 \mathrm{~h}$ quantified as a percentage of total apoptotic cells (Fig. 1d and Additional file 1), suggesting that $\mathrm{CPTH} 2$ treatment leads to cell death rather than cell cycle arrest. Collectively, these results indicate that the KAT inhibitor CPTH2 is active on both thyroid papillary $\mathrm{K} 1$ and 786-O cell lines, inhibits in vitro HAT activity in nuclear extracts, and lowers cell viability after $48 \mathrm{~h}$ treatments, thus leading to cell death.

\section{CPTH2 changes the cytoskeleton organization of CCRCC- 786-O cells and decreases invasiveness and migration}

The capability of a novel compound to counteract invasion and metastatic growth is a fundamental feature to be considered in the development of new potential antitumor drugs. We therefore analyzed the effects of CPTH2 against the invasive properties of 786-O cell line. We treated cells at increasing time with CPTH2 $(100 \mu \mathrm{M})$; after 24 and $48 \mathrm{~h}$, we observed an evident reduction of cell volume and a gross rearrangement of cytoskeleton organization with conglobation and disaggregation of the actin stress fibers and retraction of organized phila as evidenced by the phalloidin-TRITC staining (Fig. 2a). The number of visible actin stress fibers was already strongly lowered after $18 \mathrm{~h}$ of drug treatment suggesting a modulation of cell adhesion (Fig. 2b). We next assayed the adhesion capabilities of 786-O cells grown on different substrates treated with CPTH2 for 12 and $24 \mathrm{~h}$. Interestingly, CPTH2 was able to modulate cell adhesion only when 786-O cells were plated on the complex synthetic matrix Matrigel, while on single components such as fibronectin and collagen, it was substantially unaffected (Fig. 2c). This effect was evident after $48 \mathrm{~h}$ treatment hinting that the reduced adhesiveness of 786-O tumor cells is likely dependent on the concerted modulation of several different adhesion molecules. We next asked whether genes known to be involved in adhesion and migration such as integrins were affected at transcriptional level. mRNA expression profiles of selected marker genes such as the transmembrane glycoprotein CD44, involved in lymphocyte migration and metastasis [33] and integrins ITGb3, ITGb1, ITGa5, and ITGa6 [34] that were comparatively analyzed by RT-qPCR (Fig. 2d). The summary panel shows an overall coordinated upregulation after 24 and $48 \mathrm{~h}$ of treatment, indicating a clear deregulation of adhesion genes and a coordinated behavior induced by drug treatment. This result is in agreement with effects in the deregulation of integrins. It is known, in fact, that their up or downregulation $[35,36]$ is responsible to modulate cell invasion and migration in cancer microenvironment. We finally confirmed the inhibitory activity of $\mathrm{CPTH} 2$ on the cell invasiveness properties, performing an in vitro wound healing scratch tests. 786-O cells were scraped and 
a in vitro HAT assay
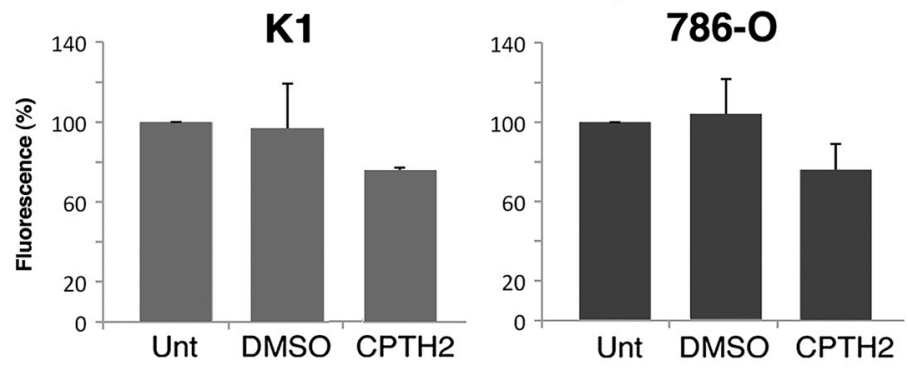

b
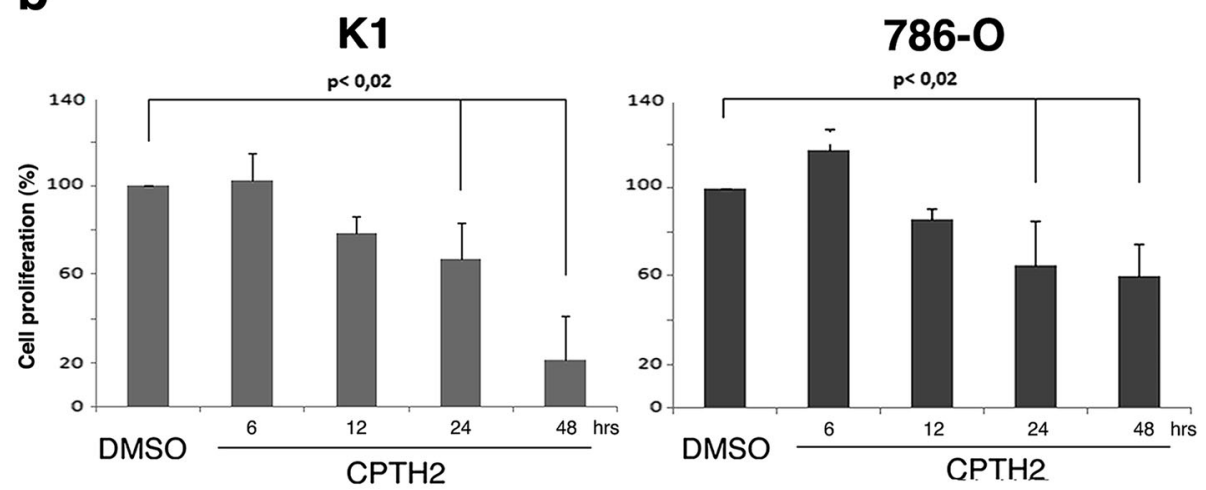

C
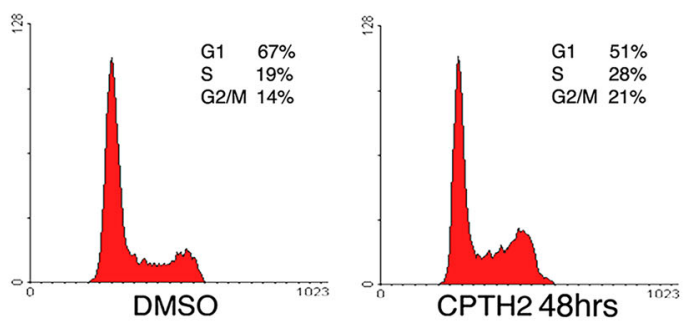

d

APOPTOSIS PROFILE
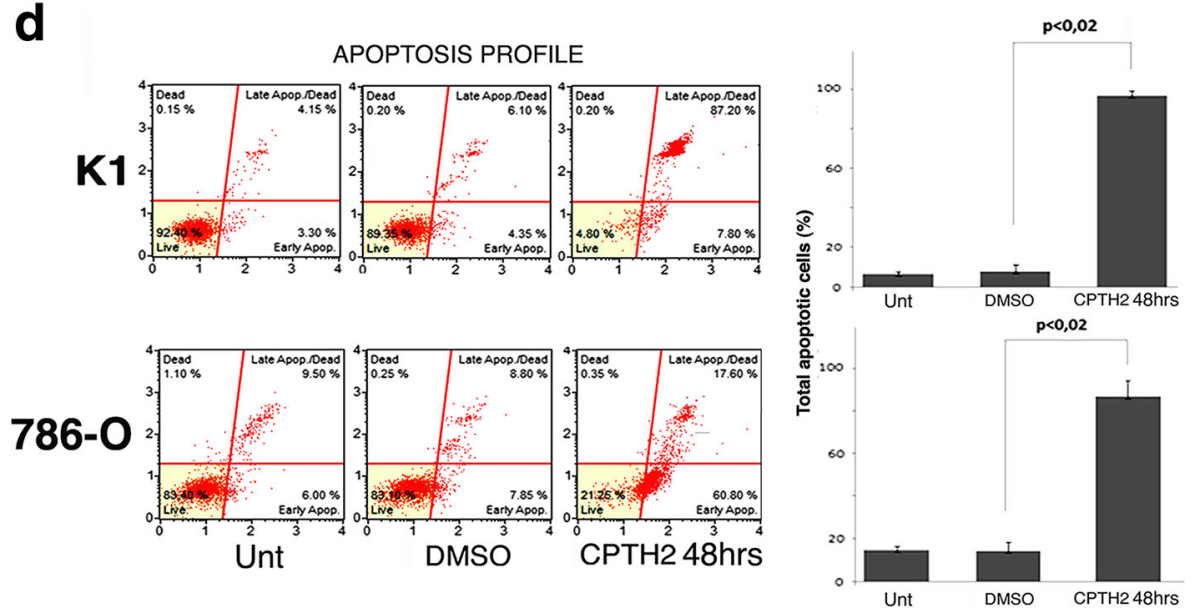

Fig. 1 HAT inhibitor CPTH2 decreases cell viability in tumor cells. a In vitro HAT activity was measured in nuclear extracts of Thyroid papillary K1 (gray) and clear cell renal carcinoma ccRCC 786-O (dark gray) cell lines treated with CPTH2 (100 $\mu \mathrm{M})$ for 24 and 48 h, respectively, and compared to untreated and DMSO samples. b Cell proliferation measured in K1 (gray) and 786-O (dark gray) cell lines in DMSO or during CPTH2 treatment at increased times (h) showed strong reduction at 48 h. c FACS analysis of 786-O cell line grown in DMSO and treated for 48 h with CPTH2. d Apoptotic FACS profile and percentage of apoptotic cells strongly enhanced after 48 h CPTH2 treatment in both K1 and 786-O cell lines 


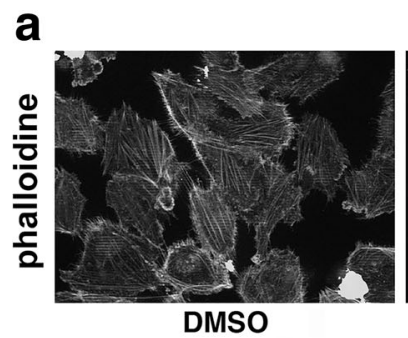

b

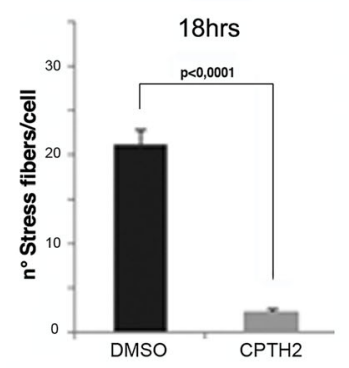

d

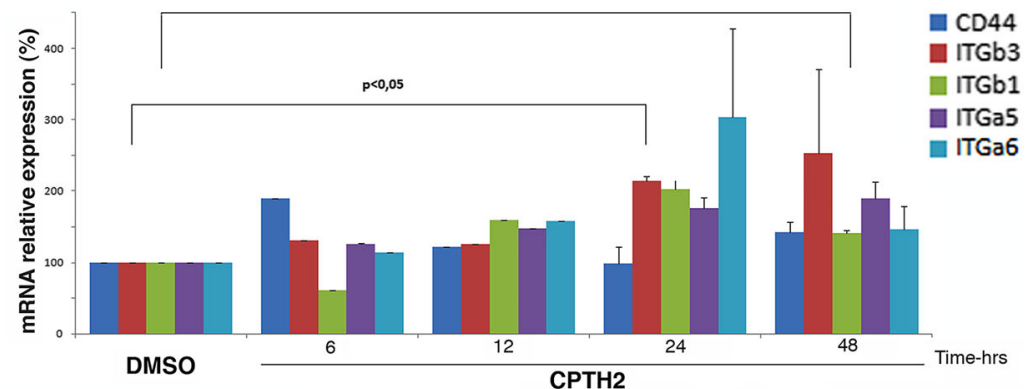

e

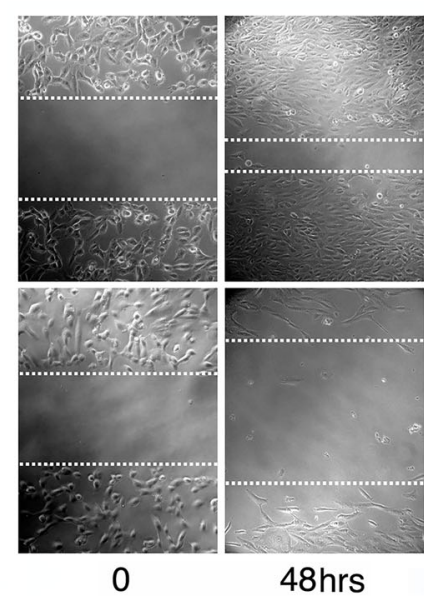

786-0

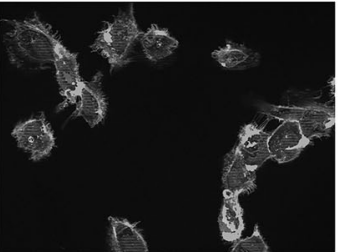

CPTH2-24hrs

C

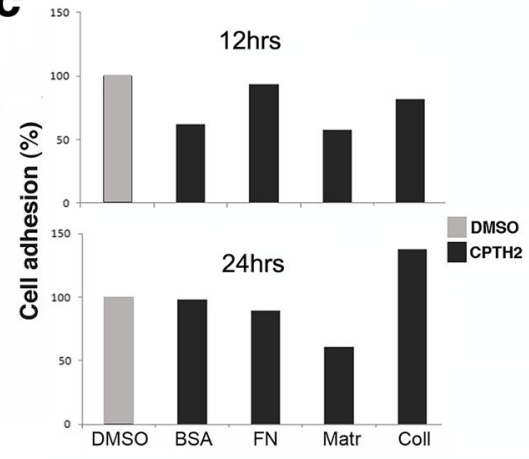

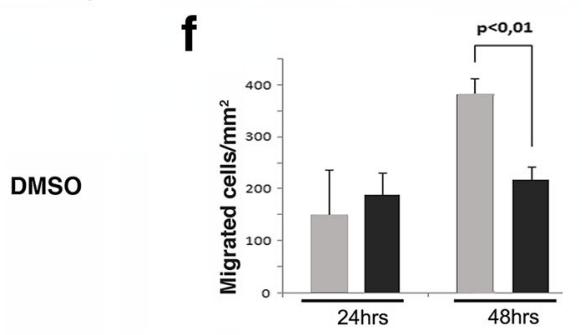

СPTH2

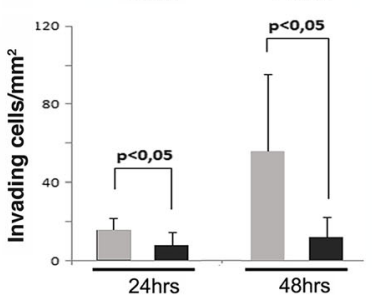

Fig. 2 CPTH2 modifies stress fiber organization and cell morphology of ccRCC 786-O cell line. a Cytoskeleton organization stained with phalloidine showed a drastic reorganization of stress fibers, adhesion placks, and cell morphology after $48 \mathrm{~h}$ of CPTH2 (100 $\mu \mathrm{M})$ treatment with respect to untreated and DMSO samples. b Percentage of stress fibers/cell after $18 \mathrm{~h}$ of CPTH2 treatment compared to DMSO sample. c Percentage of 786-O cell adhesion (\%) after 12 and $24 \mathrm{~h}$ CPTH2 treatment with respect to DMSO tested on different substrates, BSA, fibronectin (FN), matrigel (Matr.), and collagen (Coll). d mRNA expression of modulators of adhesion and migration CD44, and integrins ITGb3, ITGb1, ITGa5, and ITGa6 analyzed by qRT-PCR, shows remarkable similarity with an increase after 24/48 h of CPTH2 treatment. e Scratch test confirmed a strong inhibition of cell migration and invasiveness after $48 \mathrm{~h}$ of CPTH2 treatment compared to DMSO control. f Percentage of migrating (cells/mm²) and invading cells (cells $/ \mathrm{mm}^{2}$ ) after 24 and $48 \mathrm{~h}$ of CPTH2 (black) treatment with respect to DMSO (light gray) 
allowed to grow and migrate in $\mathrm{CPTH} 2$ versus DMSO (Fig. 2e). Results indicate that after $48 \mathrm{~h}$, it is clearly seen that while cells in DMSO were actively migrating and able to fill the gap in the presence of CPTH2 migration was severely inhibited. Migration and Matrigel invasion were tested in Boyden chambers. Figure $2 \mathrm{f}$ shows results, migration (upper panel), and invasion (lower panel) were evaluated after 24 and $48 \mathrm{~h}$ in DMSO $w / w \mathrm{CPTH} 2$ showing a drastic decrease after $48 \mathrm{~h}$ of treatment. Collectively, our data demonstrate that $\mathrm{CPTH} 2$ is capable to counteract invasion and migration of 786-O cells in culture.

\section{CPTH2 shows selectivity for KAT3B-p300}

In order to evaluate the selectivity of $\mathrm{CPTH} 2$ in the inhibition of individual KATs, we carried out an in vitro HAT assay with recombinant p300, GCN5, and PCAF in the presence of increasing concentrations of $\mathrm{CPTH} 2$ (400 and $600 \mu \mathrm{M})$ and the known KAT inhibitor anacardic acid [20, 37]. CPTH2 preferentially inhibited p300 compared to GCN5 while it did not affect PCAF (Fig. 3a). Starting from this evidence, we first analyzed the effects of CPTH2 on p300 mRNA expression in 786-O cell line, and RT-qPCR in 6 to $48 \mathrm{~h}$ time lap cultures showed that p300 mRNA expression was unaffected by $\mathrm{CPTH} 2$ treatment at transcriptional level (Fig. 3b). We next asked whether CPTH2 may act at the protein level. Since p300 can be expressed both in the cell nucleus and cytoplasm, immunocytochemistry was performed using anti-p300 antibodies on 786-O (Fig. 3c) and $\mathrm{K} 1$ thyroid cultures (Additional file 3) in untreated, DMSO control, and after $72 \mathrm{~h}$ of $\mathrm{CPTH} 2$ treatment, to better depict the eventual subcellular change of expression. Surprisingly, p300 staining decreased progressively to reach an almost complete clearing after $72 \mathrm{~h}$ of CPTH2 stimulation in both cell lines. Our analysis also revealed that CPTH2 lowered p300 protein levels on both its nuclear and cytoplasmatic localization. We wanted to assay the effects of CPTH2 on p300 in presence of proteasomal degradation. Cells were pretreated with MG 132 for $1 \mathrm{~h}$ and then grown in DMSO $w / w$ CPTH2; no relevant differences in the number of apoptotic cells nor in immunostaining intensity of p300 were obtained. These results suggest that the proteasome has not a relevant function in the decrease of p300 upon $\mathrm{CPTH} 2$ treatment. These results suggested that, even on live cells, CPTH2 may exert its main inhibitory activity on KAT3B-p300 and is able to lower the protein level independently from its cellular localization. On the basis of CPTH2 selectivity for KAT3B, we decided to investigate the effects of p300 silencing in 786-O cells. Figure 3d shows that KAT3B-p300 mRNA interference (left panel) was followed by an early drop of 786-O cell viability (right panel) comparable in value to the effect induced by treatment with CPTH2 $100 \mu \mathrm{M}$ (Fig. 1b vs. Fig. 3d). Furthermore, p300 silencing after $18 \mathrm{~h}$ resulted in a remarkable cytoskeleton rearrangement with clear drop in the number of stress fibers per cell (Fig. 3e). To provide a further demonstration that $\mathrm{CPTH} 2$ and p300si act through the same target, 786-O cells transfected with control (nc) and si-p300 RNA were grown in DMSO and treated with CPTH2 for $48 \mathrm{~h} \mathrm{(Fig.} \mathrm{3f).} \mathrm{We} \mathrm{found} \mathrm{that} \mathrm{cell} \mathrm{proliferation,} \mathrm{number} \mathrm{of}$ stress fibers, and migration showed the same values in controls and si-p300 cells, thus demonstrating full overlap between CPTH2 activity and silencing of p300. Collectively, all these results demonstrate the selectivity of $\mathrm{CPTH} 2$ in the inhibition of KAT3B-p300.

\section{CPTH2 treatment and p300si show similar effects on histone H3K18 acetylation and expression of selected cancer markers}

Increased expression of KAT3B correlates with higher acetylation of histone H3K18 in the axonal regeneration of optic nerve [38] while its and CREBB knockdown led to a global decrease of H3AcK18 in human embryonic stem cells [39]. In budding yeast, we showed a selective acetylating activity of KAT2A on H3K18 [40]. Following this line of results, we next asked whether CPTH2 might similarly affect acetylation of histone $\mathrm{H} 3$ and at selected H3K18 in 786-O cells. Western blot analysis of bulk histone preparations from 786-O cells were serially hybridized with anti-AcH3 and anti-H3AcK18 antibodies after a 48-h time course incubation with $\mathrm{CPTH} 2$ showing a reduced acetylation of both global $\mathrm{AcH} 3$ histone and H3AcK18 (Fig. 4a). Next, based on the matching between $\mathrm{CPTH} 2$ treatment and p300 silencing, we tested the global levels of AcH3 and H3AcK18 at different time points during $\mathrm{p} 300$ si treatment in 786-O confirming the decrease of AcH3 and H3AcK18 after 24 h (Fig. 4b). Immunohistochemical staining of 786-O for specific $\mathrm{H} 3$ lysines, H3AcK14, and H3AcK18 was then performed in cells treated for $48 \mathrm{~h}$ with CPTH2 (Fig. 4c). Strikingly, while the staining pattern of H3AcK14 was unaltered by $\mathrm{CPTH} 2$ treatment, the staining of H3AcK18 was drastically weakened in comparison to control and DMSO cells, suggesting that the inhibitory activity of CPTH2 was highly selective for histone H3K18 residue with respect to H3K14. The immunohistochemical analysis on p300si 786-O cells with anti-p300, as a control, antiH3AcK14, and H3AcK18 compared to untreated nc cells (Fig. 4d) showed substantially the same result. This unbiased result confirms that silencing of p300 and СРTH2 treatment induce similar effects lowering the degree of global histone H3AcK18 in a p300 dependent way. We then added a control experiment by comparing the activity of the previously described specific KAT3B inhibitor, C646 [14] with CPTH2. Western blot analysis showed that the effects of $\mathrm{C} 646$ and $\mathrm{CPTH} 2$ on inhibition of bulk AcH3, H3AcK14, and H3AcK18 were fully comparable at increasing times (Fig. 4e). To reinforce this point, we finally compared the transcriptional effects 

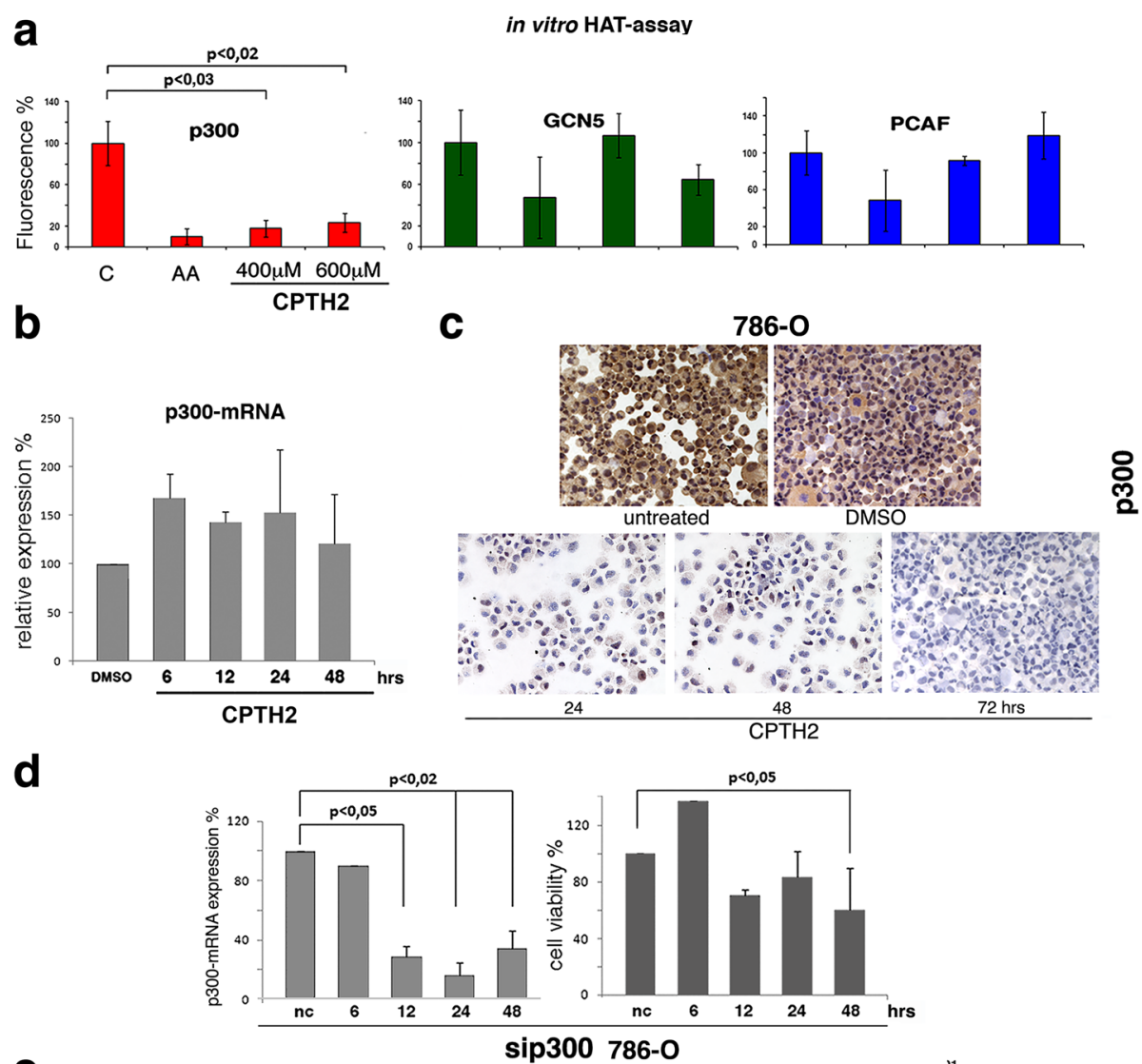

e

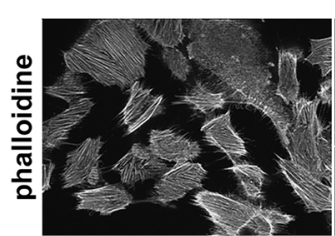

nc

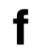

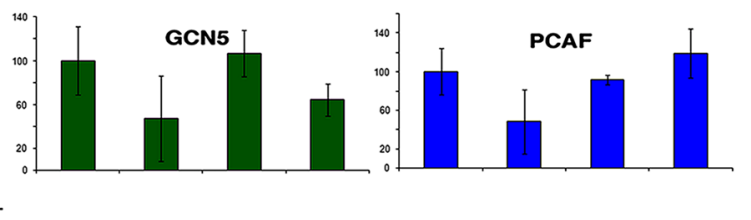

in vitro HAT-assay

○
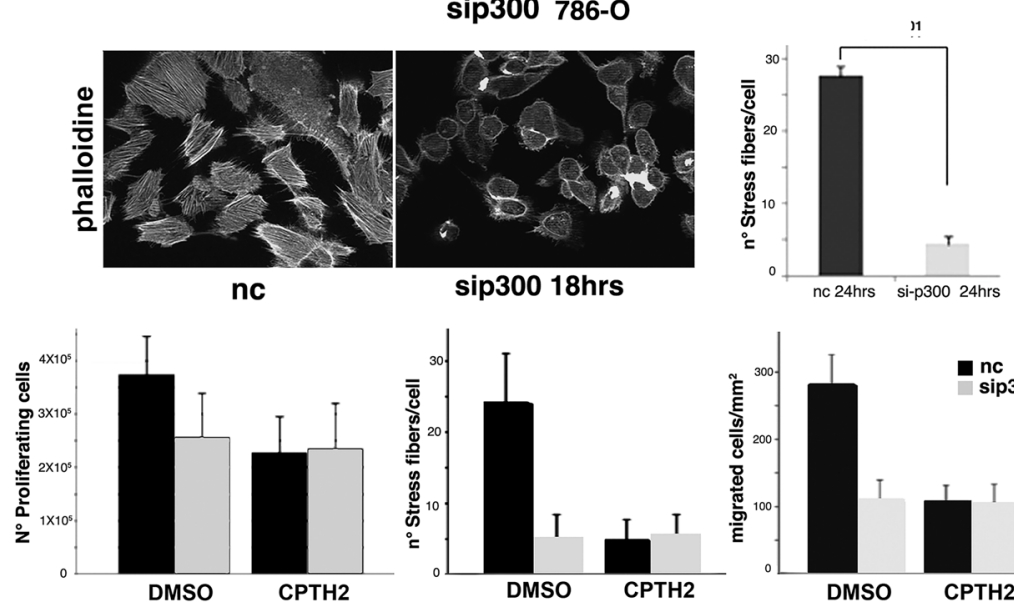

sip300 18hrs
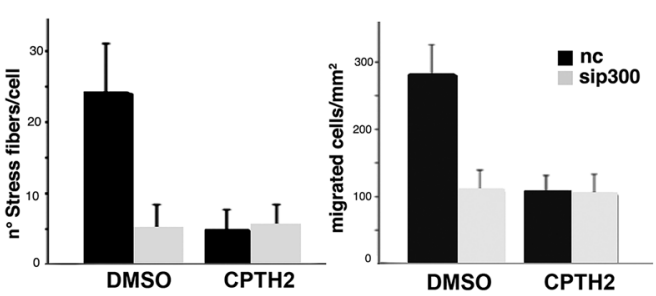

Fig. 3 CPTH2 preferentially inhibits HAT-p300 in ccRCC 786-O cells. a In vitro HAT assay was performed on recombinant p300 (red), GCN5 (green), and PCAF (blue). Control (c) in presence of HAT inhibitor anacardic acid, AA (15 $\mu \mathrm{M})$, and CPTH2 (400 and $600 \mu \mathrm{M})$. CPTH2 shows higher selectivity in the inhibition of p300. b Prolonged incubation with CPTH2 does not affect mRNA expression of p300. $\mathbf{c}$ treatment of ccRCC 786-O with CPTH2 (100 $\mu$ M) at indicated times clears the immunostaining of p300 with respect to untreated and DMSO cells. $\mathbf{d}$ Silencing of p300 in 786-O cells caused decrease of p300-mRNA expression (light gray) and lowering of cell viability (gray) with respect to nc control. e Cytoskeleton of 786-O cells silenced for p300 (18 h) was stained with phalloidine. It is heavily modified and fully comparable to the cytoskeleton of cells treated with CPTH2 shown in Fig. 2a, and histogram with percentage of stress fibers/cell found after $24 \mathrm{~h}$ p300si (light gray) compared to control, nc (dark gray). $\mathbf{f}$ Histograms reporting the number of proliferating cells, percentage of stress fiber/cell and number of migrating cells in, respectively, nc control (black) and p300si cells (gray) grown in DMSO and in CPTH2 for $48 \mathrm{~h}$

of p300si and CPTH2 treatment on the mRNA expression of three oncogenes: AKT1, TGFb2, and HIF-1a at different time points (Fig. 4f). The summary diagram of collected results showed convincingly that the expression trend of each gene in time is highly comparable in the two experimental conditions providing an additional conclusive demonstration on the convergent effects obtained by treatment of CPTH2 and silencing p300. 
a

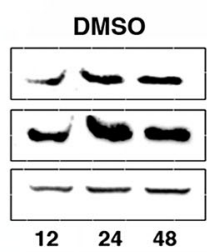

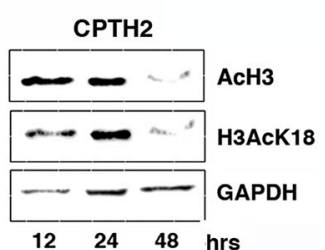

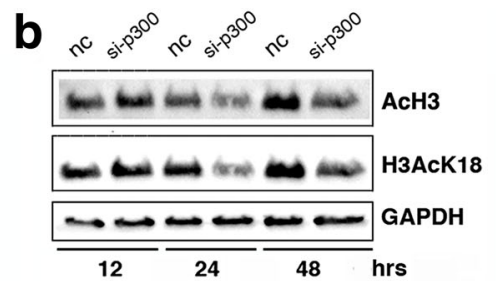

C
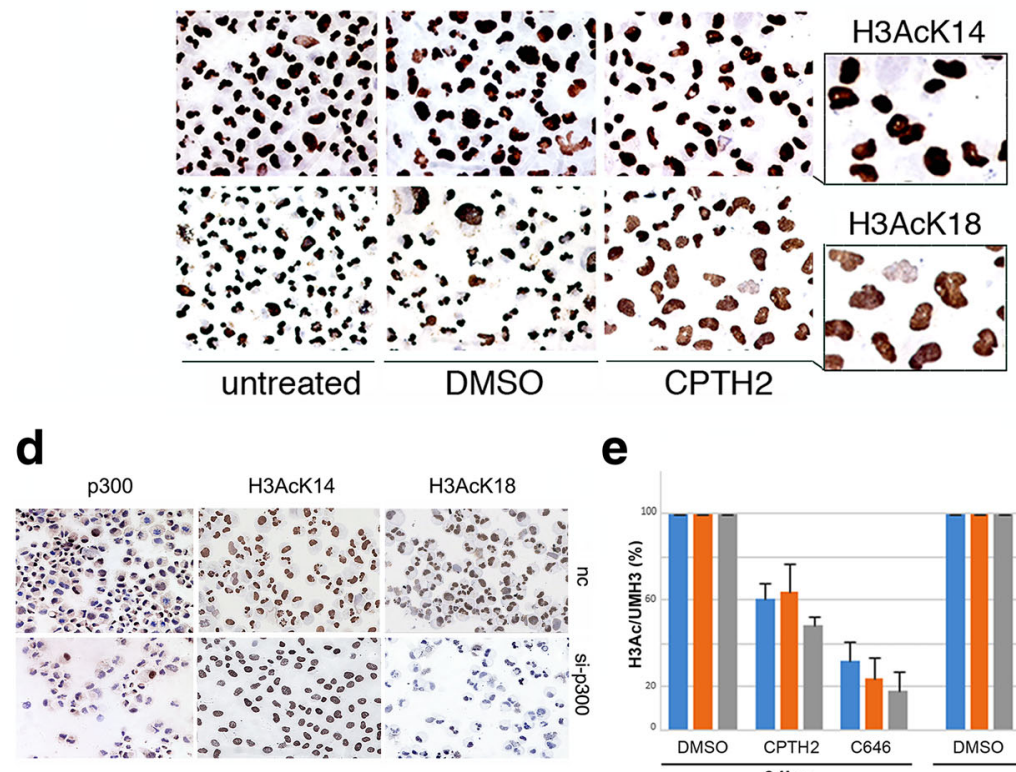

e

f
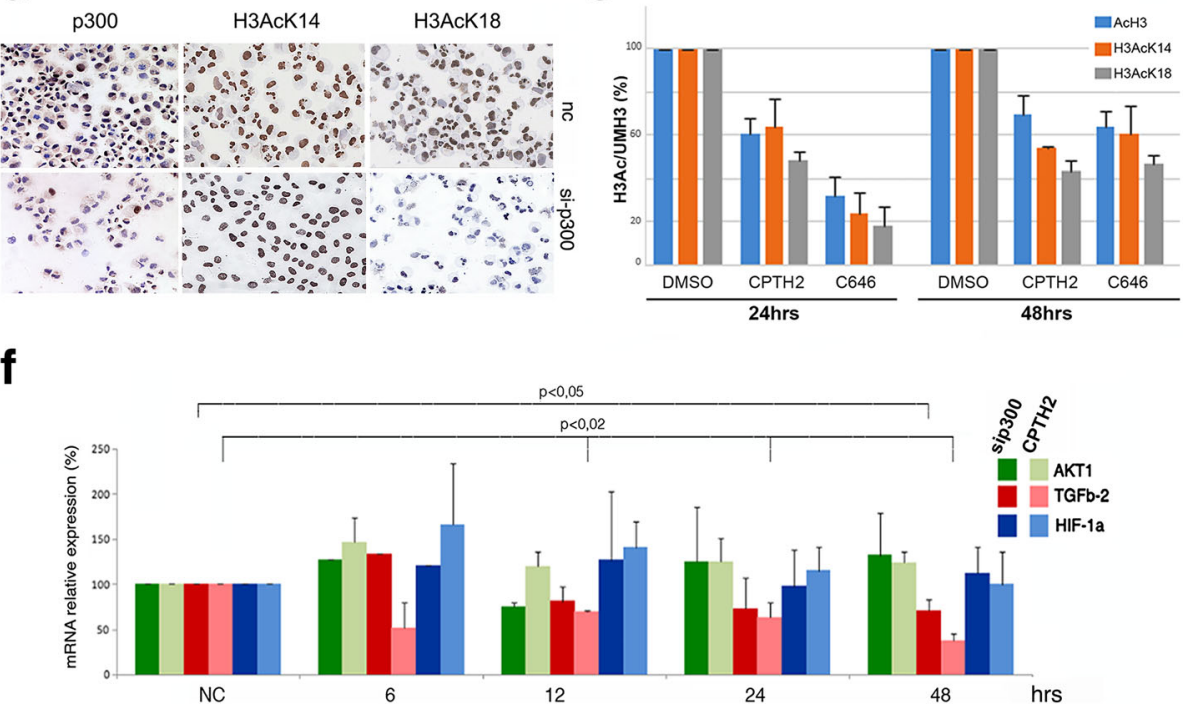

Fig. 4 Treatment with CPTH2 and p300si in cCRCC 786-O cells show similar effects. a Western blot analysis of bulk histone preparations extracted from 786-O cells at increasing times of CPTH2 (100 $\mu \mathrm{M})$ treatment sequentially hybridized with anti-AcH3, anti-H3AcK18, and anti-GAPDH as internal standard. $\mathbf{b}$ The same experiment performed in 786-O treated for p300si at increasing times in comparison with untreated $\mathrm{nc}$. $\mathbf{c}$ Immunohistochemical staining of selective histone H3AcK14 and H3AcK18 in 786-O cells untreated, in DMSO and treated with CPTH2 (100 $\mu \mathrm{M})$ for $48 \mathrm{~h}$. d The same analysis performed in 786-O cells after $48 \mathrm{~h}$ p300si and nc control, hybridized with anti-p300, anti H3AcK14, and anti H3AcK18. e Histograms show the level of AcH3, H3AcK14,

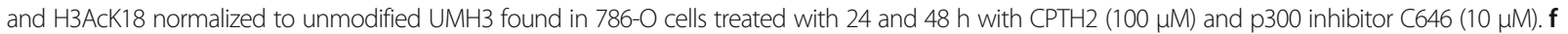
Comparison of mRNA levels of tumor markers AKT1 (green), TGFb-2 (red), and HIF-1a (blue) carried out by RT-qPCR in cells treated at increased indicated

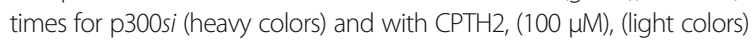

\section{Expression of p300, H3AcK18, and H3AcK14 of ccRCC ex vivo carcinoma}

To analyze whether ccRCC cells selected acetylated forms of histone H3K18 and H3K14, bulk preparations of histone nuclear proteins were extracted from $11 \mathrm{ccRCC}$ specimens and from normal adjacent tissues and tested by western blot. The results were normalized to the amount of unmodified $\mathrm{H} 3$ and expressed as arbitrary units (Fig. 5a). As shown, the amount of H3AcK18 was generally much lower than H3AcK14, and overall, the acetylation of both was extremely variable among cases. Interestingly, however, the respective acetylation of tumor versus normal paired tissue was higher for H3AcK18 and lower for H3AcK14. Furthermore, G3-stage II (nos. 6 and 7), G2stage I (nos. 13 and 23), and G3-stage I (nos. 17 and 18) $[32,41]$ were characterized by higher content of H3AcK18 and lower content of H3AcK14 in tumor with respect to normal paired tissues. Taken together, these data 
evidenced a global heterogeneity in the levels of H3AcK14 and H3AcK18 among individuals but hinted of an opposite influence of H3AcK18 and H3AcK14 residues on tumor growth. To test the hypothesis of a reciprocal behavior between H3AcK14 and H3AcK18 and the possible correlation between p300 and H3AcK18 expression as found in vitro on 786-O cell line, we decided to extend the analysis to tumor specimen from ccRCC patients after a careful tumors reevaluation. Overall, 70 ccRCC patients were entered in the study: 46 (65\%) males and 24 females (35\%). The mean age was $64.2 \pm 11.2$ years. Twenty patients (29\%) present a grade 1 and 50 grades $2-3(71 \%)$; 35 patients a stage I (50\%) and 35 at stages II-III (50\%) $[32,41]$ (Table 1). Sections from 2 to 4 different blocks for each case of ccRCC, everyone comprising normal peritumoral renal parenchyma, were immunostained with H3AcK18, H3AcK14, and KAT3B-p300 antibodies, and the results were reported as the mean percentage of stained nuclei. The choice of antibody experimental settings and parameters were chosen in order to exclude any cytoplasm staining, thus avoiding misleading results. More importantly, to avoid differential conditions in experimental setting, the cases were stained altogether in a single experiment in order to obtain a fully comparable result. Although the number of the cases analyzed in this study is limited, their distribution for sex, age, grade, and stage is representative of usual ccRCC epidemiology. As expected, expression of H3AcK18 and H3AcK14 was limited to the cell nucleus of both clear renal cell carcinoma and epithelial cells of normal kidney (podocytes and epithelial cells of the proximal and distal tubules), whereas KAT3B-p300 antibody stained both the nucleus and the cytoplasm in 42/70 ccRCC cases and 67/69 epithelial cell of the peritumoral normal kidneys. Our results have taken into consideration only the normal kidney or neoplastic epithelial cells whereas endothelial and inflammatory intra and perineoplastic cells, also expressing the three proteins, were carefully excluded. The percentage of tumor or normal epithelial cells expressing the three antibodies was highly variable among the different cases (Additional file 4). Patients' characteristics according to p300, H3AcK14, and H3AcK18 expression are summarized in Table 2. Overall, there was no significant difference in the frequency of positive cells between the tumor and adjacent normal kidney tissues for all the three antibodies used. The frequency of H3AcK18, H3AcK14, and p300 positive epithelial cells in normal tissues, although different among cases, showed similar mean + SD values independently from the sex, age, grade, and stage of the hosted tumor. Surprisingly, only the G1 tumors showed a significant variation of the three parameters with respect to their normal counterpart, suggesting that G1 tumors may show different pathway of transformation or progression (Fig. 5b). As shown in Fig. 5b and Table 2, G2-G3 ccRCC presented a significant higher expression of p300 and H3AcK18 and a lower expression of H3AcK14 compared to G1 ccRCC $(p<0.001)$. Furthermore, high-stage ccRCCs presented a significant lower expression of H3AcK14 (Table 2). Interestingly, in all the tumor cases, the expression of p300 is directly correlated with H3AcK18 and inversely to H3AcK14, Fig. 5c shows two significant cases. On the multivariable analysis, H3AcK14 and p300 were found to be independent predictors of high-grade ccRCC (Table 3). Particularly, p300 increased the risk of high-grade ccRCC by $7.6 \%$ per unit (OR 1.076, IC 1.029-1.236, $p=0.001$ ) and H3AcK14 reduced the risk of high-grade ccRCC by $3 \%$ per unit (OR 0 . 971, IC 0.943-0.999, $p=0.0041$ ). H3AcK14 was also independent predictors of high-stage ccRCC. Particularly, H3AcK14 expression reduced the risk of stages II-III by $2.5 \%$ per unit (OR 0.975, IC 0.953-0.999, $p=0.041$ ).

\section{Discussion}

In the last decades, it has been demonstrated that genes aberrantly regulated in human cancer play a fundamental role in tumor onset and progression. Overall, epigenetic regulation tuning cell differentiation in response to environmental stimuli can be considered a driving alteration of tumor progression and a response sign to therapy. Aberrant patterns of post-translational modifications of histones and cellular proteins lead to alteration of the epigenetic landscape that characterizes human diseases, from cancer to inflammatory and neurological disorders $[42,43]$. K-histone acetyltransferases (KATs) are indeed aberrantly expressed in cancer and contribute to oncogenic transformation, thus representing, more importantly, potential targets for therapeutic intervention. KAT3B-p300 is a critical regulator of hematopoiesis, and its heightened expression is recurrent in human malignancies such as prostate [44], liver [12, 45], and breast cancer and is predictive of worse prognosis. Accordingly, the activation of several oncogenes which directly sustain cancer proliferation such as STAT3, NF- $\mathrm{kB}$, and HIF1 $\alpha$ are subjected to acetylation. Furthermore, it has been highlighted the role of p300 as a coactivator in the induction of superenhancers, master hub coordinating the expression of cluster of transcriptional enhancers controlling fundamental gene circuitries responsible for cell identity [46]. p300 is engaged not only in the acetylation of nuclear histones but also of non-histone proteins such as transcription factors involved in autophagy [47], motility, and metastatic processes [48]. Collectively, these reports, as part of a vast literature, suggest many reasons why p300 represents a promising therapeutic target in the treatment of refractory cancer types [49]. Although the mechanisms that regulate p300 activity have not been yet fully highlighted, the importance of p300 intracellular localization for its activity [50-53] has acquired relevance. Lysine acetylation coregulates several cellular functions through large 
a
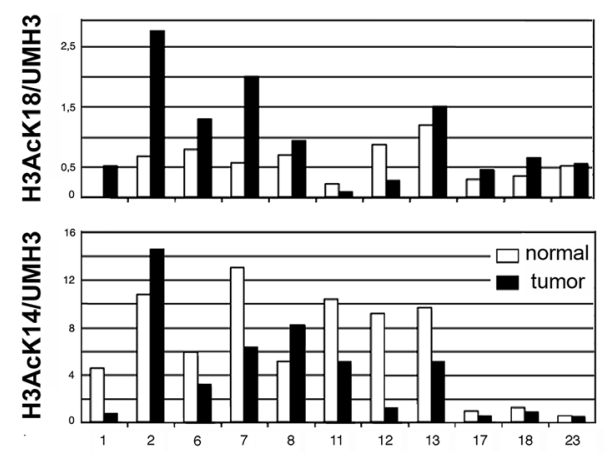

b
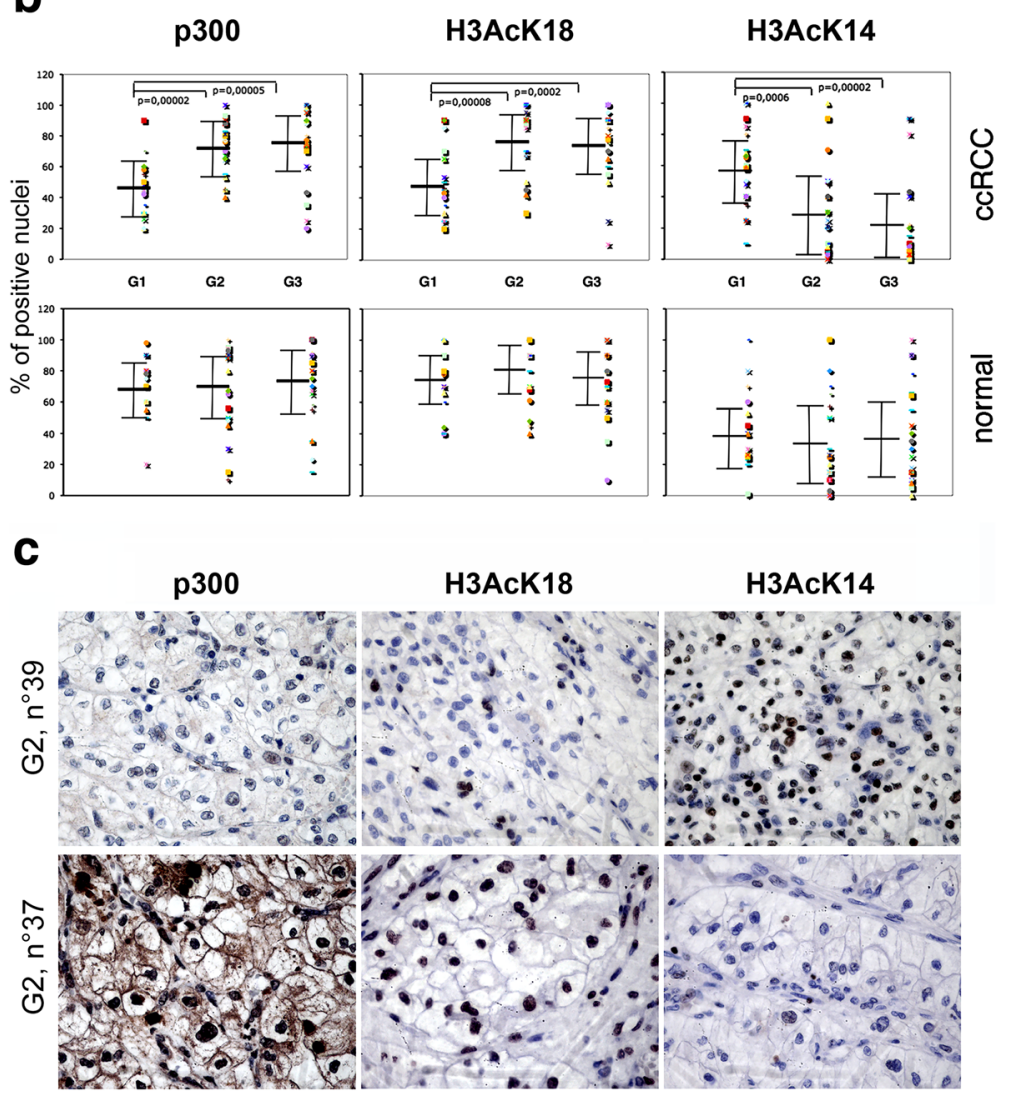

Fig. 5 HAT p300, histone residues H3AcK14, and H3AcK18 mark renal clear cell carcinoma tumor grade progression. a Histograms show the level of histone H3AcK18 and H3AcK14 normalized to unmodified UMH3 found in normal (white) and tumor tissues (black) in ccRCC patients at different grade. $\mathbf{b}$ Histograms show the percentage of positive nuclei, evaluated in parallel by immunohistochemistry with anti-p300, anti-H3AcK18, and anti-H3AcK14 antibodies in cancer and paired normal tissue sections from 70 ccRCC specimen (Table 2). When grouped by differentiation grade (G1, G2, and G3), p300 and anti-H3AcK18 show a symmetrical and significant lower percentage of positive nuclei at G1 with respect to G2-G3 ccRCC and to their paired normal tissues. On the contrary, H3AcK14 displays significant increase of positive ccRCC cells at G1 decreasing through G2 and G3 versus the percentage found in the paired normal tissue. c Immunostaining of two representative G2 ccRCC cases (nos. 39 and 37) showing opposing behavior of p300 and H3AcK18 vs H3AcK14 expression. High nuclear expression of p300 is accompanied by a cytoplasm positivity in case no. 37. Avidin Biotin Immuno-peroxidase staining; enlargement 400x

macromolecular complexes involved in chromatin remodeling, splicing, nuclear transport, and actin nucleation [54]. In pancreatic cancer, a nuclear signaling between Src and p300, with a Src-dependent phosphorylation of p300, regulates gene promoters of AT-hook (HMGA)2, SET, and SMYD3 with effects on cell migration and invasiveness of tumor cells [55]. In the cytoplasm, acetylation increases the stability of actin fibers of the cytoskeleton [56] while opposed deacetylation leads to their destabilization with consequent-reduced migration and motility of cells. In renal clear cell carcinoma 786-O cell line and in papillary thyroid K1, we have demonstrated that KAT inhibitor 
Table 2 Distribution of histone H3K18 and K14 acetylation and p300 in cCRCC tumor versus paired normal kidney according to tumor grade and stage $[32,41]$

\begin{tabular}{|c|c|c|c|c|c|c|c|c|c|}
\hline & Normal kidney & cCRCC & TVSN & CCRCC G 1 & $c C R C C G \geq 2$ & $G 1$ vs $G \geq 2$ & ccRcc stage 1 & $\begin{array}{l}\text { ccRCC } \\
\text { stage } \geq 2\end{array}$ & $\begin{array}{l}\text { Stage } 1 \text { vs } \\
\text { stage } \geq 2\end{array}$ \\
\hline $\begin{array}{l}\mathrm{H} 3 \mathrm{AcK} 14 \% \\
\text { mean } \pm \text { SD }\end{array}$ & $38.54 \pm 29.33$ & $34.26 \pm 30.86$ & 0.319 & $58.50 \pm 24.605$ & $24.56 \pm 27.753$ & 0.000 & $39.59 \pm 32.583$ & $24.04 \pm 24.775$ & 0.051 \\
\hline Male & $38.91 \pm 32.31$ & $34.85 \pm 30.34$ & 0.52 & & & & & & \\
\hline Female & $37.83 \pm 23.36$ & $33.13 \pm 32.45$ & 0.65 & & & & & & \\
\hline$M$ vs F & 0.796 & 0.715 & & & & & & & \\
\hline $\begin{array}{l}\mathrm{H} 3 \mathrm{AcK} 18 \% \\
\text { mean } \pm \text { SD }\end{array}$ & $77.02 \pm 19.99$ & $68.51 \pm 25.57$ & 0.26 & $48.65 \pm 22.335$ & $76.46 \pm 22.403$ & 0.000 & $68.76 \pm 25.848$ & $68.04 \pm 25.578$ & 0.945 \\
\hline Male & $75.83 \pm 22.91$ & $66.91 \pm 27.03$ & 0.12 & & & & & & \\
\hline Female & $71.58 \pm 22.74$ & $71.58 \pm 22.74$ & 0.14 & & & & & & \\
\hline$M$ vs F & 0.939 & 0.546 & & & & & & & \\
\hline $\begin{array}{l}\mathrm{p} 300 \% \\
\text { mean } \pm \mathrm{SD}\end{array}$ & $70.46 \pm 23.46$ & $67.73 \pm 21.17$ & 0.21 & $46.65 \pm 17.388$ & $76.16 \pm 16.133$ & 0.000 & $66.35 \pm 22.584$ & $70.38 \pm 18.332$ & 0.527 \\
\hline Male & $65.67 \pm 20.32$ & $72.67 \pm 23.82$ & 0.13 & & & & & & \\
\hline Female & $71.67 \pm 22.63$ & $66.29 \pm 22.66$ & 0.41 & & & & & & \\
\hline$M$ vs F & 0.166 & 0.189 & & & & & & & \\
\hline
\end{tabular}

CPTH2 [23] increases cell death and apoptosis, changes adhesion and cytoskeletal organization, and decreases cell invasiveness and migration. Interestingly, we showed that CPTH2 acts primarily on KAT3B-p300. Although CPTH2 was shown to inhibit GCN5 in human cells, it is also to be underlined that KAT2A-GCN5 expression in renal normal cells and in ccRCC is very low (according to Human Protein Atlas and our unpublished results). Administration of CPTH2 and silencing of p300 showed identical effects in treated cells. We also report that CPTH2 lowers the concentration of p300 at protein level both in the nucleus and in the cytoplasm suggesting that it may carry out several functions in the cell. In the cytoplasm, it may affect actin cytoskeleton stability lowering cell motility while, in the nucleus, it inhibits global levels of histone $\mathrm{H} 3$ acetylation and p300 dependent H3AcK18 [43] with several regulatory effects, such as regulation of the expression of genes and oncogenes such as AKT1, TGFb2, and HIF1a. Alteration of post-translational modifications at selected histone N-terminal residues is an emerging novel tool for early diagnosis and prognosis. Oxidative stress induced by malignant transformation of renal tubular epithelium changes global acetylation of histones H3-K9, K18, K27,

Table 3 Odds ratios (OR) and 95\% confidence interval (Cl) for predicting G2-G3 cCRCC and stage II-III cCRCC

\begin{tabular}{lllllllll}
\hline & \multicolumn{3}{l}{ Risk of G2-G3 ccRCC } & & \multicolumn{3}{l}{ Risk of stage II-III ccRCC } \\
\cline { 2 - 3 } & OR & $95 \% \mathrm{Cl}$ & $p$ & & OR & $95 \% \mathrm{Cl}$ & $p$ \\
\hline Age & 0.994 & $0.926-1.068$ & 0.875 & & 1.054 & $0.998-1.113$ & 0.062 \\
p300t & 1.076 & $1.029-1.126$ & 0.001 & & 1.003 & $0.973-1.034$ & 0.851 \\
H3AcK18 & 1.021 & $0.987-1.056$ & 0.223 & & 0.981 & $0.954-1.008$ & 0.170 \\
H3AcK14 & 0.971 & $0.943-0.999$ & 0.041 & & 0.975 & $0.953-0.999$ & 0.041 \\
\hline
\end{tabular}

and K14 [57]. Hypoacetylation of H3AcK18 is associated to prostate carcinoma with poor prognosis [58], and increase of H3AcK18 caused by absence of SIRT7 at sites of DNA damage affects the maintenance of genome integrity [59]. Lower levels of H3K3me2 and H3AcK18 are in fact predictive for higher recurrence in prostate, lung, and kidney cancer patients and can be used for distinguishing clinical outcomes of patients with substantially similar clinico-pathological variables [60]. On the basis of the effects of CPTH2 in lowering p300 and H3AcK18 and the vast literature on the relevance of this histone mark as prognosticator in cancer patients, we wanted to extend the analysis of histone $\mathrm{H} 3$ acetylation at K18 and K14 along with p300 in 70 cases of ccRCC tumor patients (listed in Table 1). In the presented study, we started from western blot analysis on global levels of H3AcK18 and H3AcK14 performed by comparison of nuclear extracts from tumor tissue and peritumoral normal epithelium of each single patient, which revealed a great heterogeneity in the global levels of H3AcK14 and H3AcK18 with respect to unmodified $\mathrm{H} 3$ among patients. This observation motivated us to extend our study to 70 ccRCC cases grouped for tumor grade. To be sure to exclude from our tissue analysis immunostaining due to non-specific cytoplasm background, we used high dilutions of H3AcK18, H3AcK14 antibodies (methods), and this allowed us to stain, exclusively, cell nuclei and exclude false positive and cross reaction (Fig. 4c, d and Additional file 3). Statistical analysis of our collected results showed that p300 and H3AcK18 levels gave identical profiles supporting selectivity of p300 for H3AcK18 also in ccRCC specimens. Importantly, the analysis showed an identical pattern of p300, H3AcK18, and H3AcK14 in the normal peritumoral 
tissue of all patients confirming the relevance of analyzing normal epithelium in our screening. Lower p300/ H3AcK18 opposed to higher H3AcK14 in low-grade ccRCC, G1 cases with respect to normal epithelium was observed. In addition, with tumor worsening to G2-G3 grade, while p300/H3AcK18 come back to levels found in normal tissues, H3AcK14 showed a significant, progressive decrease (Fig. $5 \mathrm{~b}$ ) as summarized in Table 2. The opposed degree of H3AcK14 vs H3AcK18/p300 expression is significatively restricted to G1 tumors and may therefore represent an important epigenetic signature of lowgrade ccRCC. Notably, conflicting results have been reported on the expression levels of histone H3 acetylation and specific H3AcK18 and H3AcK14 in cancer. While conflicting results reported the relevance of the acetylation of H3, H3K18 and H3K14 in ccRCC progression $[9,61]$ warrant are issued for a more thorough study of ccRCC from different and relevant casuistic and analytical procedures. Collectively, the presented study reports the identification of a novel epigenetic signature for tracing ccRCC tumor tissues based on low-p300/H3AcK18 vs high-H3AcK14 ratio in global histone $\mathrm{H} 3$ acetylation, distinctive of low-grade G1 tumors, and prognosticators for tumor aggressiveness. Further molecular analysis for cancer markers such as expression of oncogenes and oncosuppressors or noncoding RNAs can be developed to identify additional characterizing features for the classification of high- or low-H3K18/K14 ratio found in ccRCC low-grade G1 tumors.

\section{Conclusion}

The p300 inhibitor CPTH2 lowers cell invasiveness and viability in ccRCC 786-O cell line. It is a promising compound for counteracting the increase of p300 and H3AcK18 found in higher grade G2, G3 ccRCC tumor tissues. Finally, the opposed ratio of p300-H3AcK18 vs H3AcK14 represents a novel prognosticator signature of low grade, and G1 ccRCC tumors and $\mathrm{CPTH} 2$ may efficiently counteract the increasing of both p300 and H3AcK18 in tumor progression.

\section{Additional files}

Additional file 1: Cell cycle progression is not affected by treatment of cCRCC 786-O cell line with CPTH2. FACS analysis of cCRCC 786-O cell line treated with DMSO w/W CPTH2 $(100 \mu \mathrm{M})$ at increasing times. Apoptotic profiles of cCRCC 786-O and papillary thyroid K1 cell lines untreated and grown in DMSO w/w CPTH2 at increasing times. (TIFF $24906 \mathrm{~kb}$ )

Additional file 2: 786-O cells grown in DMSO W/W CPTH2 for 24 and $48 \mathrm{~h}$ and immunostained with anti-Ki67 and anti-cyclin D1 show that CPTH2 treatment does not affect cell cycle progression. (TIFF $24905 \mathrm{~kb}$ )

Additional file 3: Immunostaining of K1 papyllary thyroid cells with p300 antibody after $72 \mathrm{~h}$ of treatment with CPTH2 $(100 \mu \mathrm{M})$ compared to untreated and DMSO controls. Apoptotic percentage of 786-O cells treated with proteasome inhibitor MG-132 (1 h) and then incubated in DMSO w/w CPTH2 shows no significative changes of the apoptotic profiles compared to the untreated controls. p300 immunostaining of 786-O cells were pretreated for $1 \mathrm{~h}$ with proteasome inhibitor MG132, then grow in DMSO w/w CPTH2 for $18 \mathrm{~h}$ suggest that there is no significative proteolysis of p300 upon inhibition of the proteasome. (TIFF $30444 \mathrm{~kb}$ )

Additional file 4: Immunostaining of tissue sections from cCRCC tumor and normal tissues with p300, H3AcK18, and H3AcK14 antibodies. Two opposite cases are shown, patient no. 1 with low p300/H3AcK18 vs. high H3AcK14. Patient no. 41, the opposite, high p300/H3AcK18 vs. low H3ACK14. (TIFF 37242 kb)

\begin{abstract}
Abbreviations
C646: KAT3B-p300 inhibitor; ccRCC: Clear cell renal carcinoma; CPTH2: Cyclopentylidene-[4-(4-chlorophenyl)thiazol-2-yl)hydrazone; K1: Papillary thyroid cancer cells; KAT: K-Histone acetyltransferase; KAT2A: GCN5; KAT3B: p300
\end{abstract}

\section{Acknowledgements}

The authors wish to thank Giuseppe Pisaneschi for technical assistance to P. Filetici.

\section{Funding}

E.Cocco was supported by the AV7'-PRIN 2011 (2010W4J4RM_004). M.Leo was a recipient of PhD grant in the Cell Biology and Development, La Sapienza Rome University. The work was financed by the A.Vecchione-AIRC 2016 (IG16862) and A. Mai-PRIN 2016 (2TE5PK), A. Mai-AIRC 2016 (19162).

\section{Availability of data and materials}

All data generated during this study are included in the publication and in figures (text and additional files).

\section{Authors' contributions}

AS and PF contributed equally to this work as co-corresponding authors, principal investigators, planning experimental strategy, interpretation of data, writing, and revision of the manuscript with conclusions. AV assisted in discussing the results and ms revision. EC, ML, CC, SDV, and ADN contributed to the experimental part. $\mathrm{AM}$ and DR were responsible for the synthesis and characterization of the CPTH2 compound. AS was responsible for the immunohistochemical analysis of the tissues. PF was responsible for the epigenetic interpretation of the results and analysis of histone PTMs. CDN provided the kidney biopsies and statistical analysis of patient tissues. All authors read and approved the final manuscript.

\section{Ethics approval and consent to participate}

The use of the histological material was authorized by personal patient consensus according to S. Andrea Hospital policy form.

\section{Consent for publication}

All authors approved the publication of the submitted paper.

\section{Competing interests}

The authors declare that they have no competing interests.

\section{Publisher's Note}

Springer Nature remains neutral with regard to jurisdictional claims in published maps and institutional affiliations.

\footnotetext{
Author details

${ }^{1}$ Surgical Pathology Units, Department of Clinical and Molecular Medicine, Ospedale Sant'Andrea, La Sapienza University, Rome, Italy. ²Department of Biology and Biotechnology "C. Darwin", La Sapienza University of Rome, Rome, Italy. 'Department of Immunology, IRCCS Bambino Gesù Children's Hospital, Rome, Italy. ${ }^{4}$ Institute of Molecular Biology and Pathology-CNR, La Sapienza University of Rome, P.le, A. Moro 5, Rome, Italy. ${ }^{5}$ Department of Drug Chemistry and Technology, Istituto Pasteur Italia - Fondazione Cenci Bolognetti, La Sapienza University, P.le Aldo Moro, 5, 00185 Rome, Italy. ${ }^{6}$ rology Unit, Department of Clinical and Molecular Medicine, Ospedale Sant'Andrea, La Sapienza University, Rome, Italy.
} 


\section{Received: 16 January 2018 Accepted: 14 March 2018}

\section{Published online: 04 April 2018}

\section{References}

1. Znaor A, Lortet-Tieulent J, Laversanne M, Jemal A, Bray F. International variations and trends in renal cell carcinoma incidence and mortality. Eur Urol. 2015;67:519-30.

2. Gudbjartsson T, Hardarson S, Petursdottir V, Thoroddsen A, Magnusson J, Einarsson GV. Histological subtyping and nuclear grading of renal cell carcinoma and their implications for survival: a retrospective nation-wide study of 629 patients. Eur Urol. 2005;48:593-600.

3. Brown C. Targeted therapy: an elusive cancer target. Nature. 2016;537:S106-8.

4. Maher ER. Von Hippel-Lindau disease. Curr Mol Med. 2004:4:833-42.

5. Dalgliesh GL, Furge K, Greenman C, Chen L, Bignell G, Butler A, Davies H, Edkins S, Hardy C, Latimer C, et al. Systematic sequencing of renal carcinoma reveals inactivation of histone modifying genes. Nature. 2010;463:360-3.

6. Varela I, Tarpey P, Raine K, Huang D, Ong CK, Stephens P, Davies H, Jones D, Lin ML, Teague J, et al. Exome sequencing identifies frequent mutation of the SWI/SNF complex gene PBRM1 in renal carcinoma. Nature. 2011;469:539-42.

7. Guo G, Gui Y, Gao S, Tang A, Hu X, Huang Y, Jia W, Li Z, He M, Sun L, et al. Frequent mutations of genes encoding ubiquitin-mediated proteolysis pathway components in clear cell renal cell carcinoma. Nat Genet. 2011:44:17-9.

8. Wang Y, Zhang R, Wu D, Lu Z, Sun W, Cai Y, Wang C, Jin J. Epigenetic change in kidney tumor: downregulation of histone acetyltransferase MYST1 in human renal cell carcinoma. J Exp Clin Cancer Res. 2013;32:8.

9. Mosashvilli D, Kahl P, Mertens C, Holzapfel S, Rogenhofer S, Hauser S, Buttner R, Von Ruecker A, Muller SC, Ellinger J. Global histone acetylation levels: prognostic relevance in patients with renal cell carcinoma. Cancer Sci. 2010;101:2664-9.

10. Minardi D, Lucarini G, Filosa A, Zizzi A, Milanese G, Polito M Jr, Polito M, Di Primio R, Montironi R, Muzzonigro G. Do DNA-methylation and histone acetylation play a role in clear cell renal carcinoma? Analysis of radical nephrectomy specimens in a long-term follow-up. Int J Immunopathol Pharmacol. 2011;24:149-58.

11. Gayther SA, Batley SJ, Linger L, Bannister A, Thorpe K, Chin SF, Daigo Y, Russell P, Wilson A, Sowter HM, et al. Mutations truncating the EP300 acetylase in human cancers. Nat Genet. 2000;24:300-3.

12. Li M, Luo RZ, Chen JW, Cao Y, Lu JB, He JH, Wu QL, Cai MY. High expression of transcriptional coactivator p300 correlates with aggressive features and poor prognosis of hepatocellular carcinoma. J Transl Med. 2011;9:5.

13. Fu M, Wang C, Reutens AT, Wang J, Angeletti RH, Siconolfi-Baez L, Ogryzko V, Avantaggiati ML, Pestell RG. p300 and p300/CAMP-response elementbinding protein-associated factor acetylate the androgen receptor at sites governing hormone-dependent transactivation. J Biol Chem. 2000;275: 20853-60.

14. Bowers EM, Yan G, Mukherjee C, Orry A, Wang L, Holbert MA, Crump NT, Hazzalin CA, Liszczak G, Yuan H, et al. Virtual ligand screening of the p300/ CBP histone acetyltransferase: identification of a selective small molecule inhibitor. Chem Biol. 2010;17:471-82.

15. Santer FR, Hoschele PP, Oh SJ, Erb HH, Bouchal J, Cavarretta IT, Parson W, Meyers DJ, Cole PA, Culig Z. Inhibition of the acetyltransferases p300 and CBP reveals a targetable function for p300 in the survival and invasion pathways of prostate cancer cell lines. Mol Cancer Ther. 2011;10:1644-55.

16. Yan G, Eller MS, Elm C, Larocca CA, Ryu B, Panova IP, Dancy BM, Bowers EM, Meyers D, Lareau L, et al. Selective inhibition of p300 HAT blocks cell cycle progression, induces cellular senescence, and inhibits the DNA damage response in melanoma cells. J Invest Dermatol. 2013;133:2444-52.

17. Fermento ME, Gandini NA, Salomon DG, Ferronato MJ, Vitale CA, Arevalo J, Lopez Romero A, Nunez M, Jung M, Facchinetti MM, Curino AC. Inhibition of p300 suppresses growth of breast cancer. Role of p300 subcellular localization. Exp Mol Pathol. 2014;97:411-24.

18. Kanao K, Mikami S, Mizuno R, Shinojima T, Murai M, Oya M. Decreased acetylation of histone $\mathrm{H} 3$ in renal cell carcinoma: a potential target of histone deacetylase inhibitors. J Urol. 2008;180:1131-6.

19. Stimson L, Rowlands MG, Newbatt YM, Smith NF, Raynaud Fl, Rogers P, Bavetsias V, Gorsuch S, Jarman M, Bannister A, et al. Isothiazolones as inhibitors of PCAF and p300 histone acetyltransferase activity. Mol Cancer Ther. 2005;4:1521-32

20. Eliseeva ED, Valkov V, Jung $M$, Jung MO. Characterization of novel inhibitors of histone acetyltransferases. Mol Cancer Ther. 2007;6:2391-8.
21. Gajer JM, Furdas SD, Grunder A, Gothwal M, Heinicke U, Keller K, Colland F, Fulda S, Pahl HL, Fichtner l, et al. Histone acetyltransferase inhibitors block neuroblastoma cell growth in vivo. Oncogene. 2015;4:e137.

22. Xu LX, Li ZH, Tao YF, Li RH, Fang F, Zhao H, Li G, Li YH, Wang J, Feng X, Pan J. Histone acetyltransferase inhibitor II induces apoptosis in glioma cell lines via the p53 signaling pathway. J Exp Clin Cancer Res. 2014;33:108.

23. Chimenti F, Bizzarri B, Maccioni E, Secci D, Bolasco A, Chimenti P, Fioravanti R, Granese A, Carradori S, Tosi F, et al: A novel histone acetyltransferase inhibitor modulating Gcn5 network: cyclopentylidene-[4-(4'chlorophenyl)thiazol-2-yl)hydrazone. J Med Chem 2009, 52:530-536.

24. Lin S, Nazif K, Smith A, Baas PW, Smith GM. Histone acetylation inhibitors promote axon growth in adult dorsal root ganglia neurons. J Neurosci Res. 2015;93:1215-28.

25. Ablack JN, Cohen M, Thillainadesan G, Fonseca GJ, Pelka P, Torchia J, Mymryk JS. Cellular GCN5 is a novel regulator of human adenovirus E1Aconserved region 3 transactivation. J Virol. 2012;86:8198-209.

26. Kamiya T, Machiura M, Makino J, Hara H, Hozumi I, Adachi T. Epigenetic regulation of extracellular-superoxide dismutase in human monocytes. Free Radic Biol Med. 2013;61:197-205.

27. Li G, White CA, Lam T, Pone EJ, Tran DC, Hayama KL, Zan H, Xu Z, Casali P. Combinatorial H3K9acS10ph histone modification in lgH locus $\mathrm{S}$ regions targets 14-3-3 adaptors and AID to specify antibody class-switch DNA recombination. Cell Rep. 2013;5:702-14.

28. Yin $\mathrm{W}$, Jin HJ, Zhao W, Gao B, Fang J, Wei J, Zhang DD, Zhang J, Fang D. The histone acetyltransferase GCN5 expression is elevated and regulated by c-Myc and E2F1 transcription factors in human colon cancer. Gene Expr. 2015;16:187-96.

29. Trisciuoglio D, Ragazzoni Y, Pelosi A, Desideri M, Carradori S, Gabellini C, Maresca G, Nescatelli R, Secci D, Bolasco A, et al. CPTH6, a thiazole derivative, induces histone hypoacetylation and apoptosis in human leukemia cells. Clin Cancer Res. 2012;18:475-86.

30. Rodriguez LG, Wu X, Guan JL. Wound-healing assay. Methods Mol Biol. 2005;294:23-9.

31. Geback T, Schulz MM, Koumoutsakos P, Detmar M. TScratch: a novel and simple software tool for automated analysis of monolayer wound healing assays. BioTechniques. 2009;46:265-74.

32. Edge SB, Byrd SR, Compton CC, Fritz AG, Greene FL, Trotti A. AJCC cancer staging manual. 7th ed. New York NY: Springer-Verlag; 2010.

33. Li G, Gao Y, Cui Y, Zhang T, Cui R, Jiang Y, Shi J. Overexpression of CD44 is associated with the occurrence and migration of non-small cell lung cancer. Mol Med Rep. 2016;14:3159-67.

34. Zheng W, Jiang C, Li R. Integrin and gene network analysis reveals that ITGA5 and ITGB1 are prognostic in non-small-cell lung cancer. Onco Targets Ther. 2016;9:2317-27.

35. Hood JD, Cheresh DA. Role of integrins in cell invasion and migration. Nat Rev Cancer. 2002;2:91-100.

36. Ryu J, Koh Y, Park H, Kim DY, Kim DC, Byun JM, Lee HJ, Yoon SS. Highly expressed integrin-alpha8 induces epithelial to mesenchymal transitionlike features in multiple myeloma with early relapse. Mol Cells. 2016;39: 898-908.

37. Brown JA, Bourke E, Eriksson LA, Kerin MJ. Targeting cancer using KAT inhibitors to mimic lethal knockouts. Biochem Soc Trans. 2016:44:979-86.

38. Gaub P, Joshi Y, Wuttke A, Naumann U, Schnichels S, Heiduschka P, Di Giovanni S. The histone acetyltransferase p300 promotes intrinsic axonal regeneration. Brain. 2011;134:2134-48.

39. Li B, Su T, Ferrari R, Li JY, Kurdistani SK. A unique epigenetic signature is associated with active DNA replication loci in human embryonic stem cells. Epigenetics. 2014;9:257-67.

40. Canzonetta C, Leo M, Guarino SR, Montanari A, Francisci S, Filetici P. SAGA complex and Gcn5 are necessary for respiration in budding yeast. Biochim Biophys Acta. 1863;2016:3160-8.

41. Delahunt B, Cheville JC, Martignoni G, Humphrey PA, Magi-Galluzzi C, McKenney J, Egevad L, Algaba F, Moch H, Grignon DJ, et al. The International Society of Urological Pathology (ISUP) grading system for renal cell carcinoma and other prognostic parameters. Am J Surg Pathol. 2013;37:1490-504.

42. Wapenaar H, Dekker FJ. Histone acetyltransferases: challenges in targeting bi-substrate enzymes. Clin Epigenetics. 2016:8:59.

43. Dutta R, Tiu B, Sakamoto KM. CBP/p300 acetyltransferase activity in hematologic malignancies. Mol Genet Metab. 2016;119:37-43.

44. Heemers HV, Debes JD, Tindall DJ. The role of the transcriptional coactivator p300 in prostate cancer progression. Adv Exp Med Biol. 2008;617:535-40. 
45. Yokomizo C, Yamaguchi $K$, Itoh $Y$, Nishimura T, Umemura A, Minami M, Yasui K, Mitsuyoshi H, Fujii H, Tochiki N, et al. High expression of p300 in HCC predicts shortened overall survival in association with enhanced epithelial mesenchymal transition of HCC cells. Cancer Lett. 2011:310:140-7.

46. Hnisz D, Abraham BJ, Lee TI, Lau A, Saint-Andre V, Sigova AA, Hoke HA, Young RA. Super-enhancers in the control of cell identity and disease. Cell. 2013;155:934-47.

47. Lee $\mid \mathrm{H}$, Finkel T. Regulation of autophagy by the p300 acetyltransferase. J Biol Chem. 2009;284:6322-8.

48. Yang Y, Rao R, Shen J, Tang Y, Fiskus W, Nechtman J, Atadja P, Bhalla K. Role of acetylation and extracellular location of heat shock protein 90alpha in tumor cell invasion. Cancer Res. 2008:68:4833-42.

49. Dekker FJ, Haisma HJ. Histone acetyl transferases as emerging drug targets. Drug Discov Today. 2009;14:942-8.

50. Chen J, Halappanavar S, Th' ng JP, Li Q. Ubiquitin-dependent distribution of the transcriptional coactivator p300 in cytoplasmic inclusion bodies. Epigenetics. 2007;2:92-9.

51. Mackeh R, Lorin S, Ratier A, Mejdoubi-Charef N, Baillet A, Bruneel A, Hamai A, Codogno P, Pous C, Perdiz D. Reactive oxygen species, AMP-activated protein kinase, and the transcription cofactor p300 regulate alpha-tubulin acetyltransferase-1 (alphaTAT-1/MEC-17)-dependent microtubule hyperacetylation during cell stress. J Biol Chem. 2014;289:11816-28.

52. Sebti S, Prebois C, Perez-Gracia E, Bauvy C, Desmots F, Pirot N, Gongora C, Bach AS, Hubberstey AV, Palissot V, et al. BAT3 modulates p300-dependent acetylation of p53 and autophagy-related protein 7 (ATG7) during autophagy. Proc Natl Acad Sci U S A. 2014;111:4115-20.

53. Shi D, Pop MS, Kulikov R, Love IM, Kung AL, Grossman SR. CBP and p300 are cytoplasmic E4 polyubiquitin ligases for p53. Proc Natl Acad Sci U S A. 2009; 106:16275-80.

54. Choudhary C, Kumar C, Gnad F, Nielsen ML, Rehman M, Walther TC, Olsen JV, Mann M. Lysine acetylation targets protein complexes and co-regulates major cellular functions. Science. 2009;325:834-40.

55. Paladino D, Yue P, Furuya H, Acoba J, Rosser CJ, Turkson J. A novel nuclear Src and p300 signaling axis controls migratory and invasive behavior in pancreatic cancer. Oncotarget. 2016;7:7253-67.

56. Zencheck WD, Xiao H, Weiss LM. Lysine post-translational modifications and the cytoskeleton. Essays Biochem. 2012;52:135-45.

57. Mahalingaiah PK, Ponnusamy L, Singh KP. Oxidative stress-induced epigenetic changes associated with malignant transformation of human kidney epithelial cells. Oncotarget. 2017;8:11127-43.

58. Seligson DB, Horvath S, Shi T, Yu H, Tze S, Grunstein M, Kurdistani SK. Global histone modification patterns predict risk of prostate cancer recurrence. Nature. 2005;435:1262-6.

59. Vazquez BN, Thackray JK, Simonet NG, Kane-Goldsmith N, Martinez-Redondo P, Nguyen T, Bunting S, Vaquero A, Tischfield JA, Serrano L. SIRT7 promotes genome integrity and modulates non-homologous end joining DNA repair. EMBO J. 2016; 35:1488-503.

60. Seligson DB, Horvath S, McBrian MA, Mah V, Yu H, Tze S, Wang Q, Chia D, Goodglick L, Kurdistani SK. Global levels of histone modifications predict prognosis in different cancers. Am J Pathol. 2009;174:1619-28.

61. Godlewski J, Krazinski BE, Kowalczyk AE, Kiewisz J, Kiezun J, Kwiatkowski P, Sliwinska-Jewsiewicka A, Wierzbicki PW, Kmiec Z. Expression and prognostic significance of EP300, TP53 and BAX in clear cell renal cell carcinoma. Anticancer Res. 2017;37:2927-37.

\section{Submit your next manuscript to BioMed Central and we will help you at every step:}

- We accept pre-submission inquiries

- Our selector tool helps you to find the most relevant journal

- We provide round the clock customer support

- Convenient online submission

- Thorough peer review

- Inclusion in PubMed and all major indexing services

- Maximum visibility for your research

Submit your manuscript at www.biomedcentral.com/submit 